\title{
ESTUDIO CUALITATIVO DEL PROCESO DE ADAPTACIÓN E INCLUSIÓN DE UN GRUPO DE ESTUDIANTES DE EDUCACIÓN SUPERIOR CON DISCAPACIDAD DE LA UNIVERSIDAD DE MAGALLANES
}

\author{
OSKARINA PALMA ${ }^{a}$, XIMENA SOTO $^{a}$, CAMILA BARRÍA $^{a}$, XIMENA LUCERO $^{a}$, \\ DANIEL MELLA ${ }^{a}$, YARITZA SANTANA ${ }^{a} \&$ ENRIQUE SEGUEL
}

\section{RESUMEN}

De acuerdo a la ciencia de la ocupación y la justicia ocupacional, la participación e inclusión en ocupaciones significativas, resulta fundamental para el desarrollo de las personas y de las comunidades, sin embargo, esta inclusión no siempre se ve favorecida en todos los espacios públicos. El ámbito de la educación ha desarrollado un avance importante en esta materia principalmente en sus niveles primarios, potenciando proyectos como el de integración escolar, con lo cual se ha dado espacio a alumnos en situación de discapacidad. Estos proyectos no se han incorporado a la educación superior, por lo cual los alumnos deben crear sus propias estrategias para la inclusión ya que los ambientes tanto físicos como sociales no siempre están preparados para responder a las necesidades particulares de los alumnos con distintas discapacidades y otorgar un real y equitativo acceso a la educación.

Esta investigación busca obtener mayores antecedentes acerca de los procesos de inclusión y adaptación de un grupo de jóvenes con discapacidad en la Universidad de Magallanes, con el fin de aportar de manera concreta a estas políticas. Para esto, se utilizó la metodología cualitativa, considerando la experiencia de 15 estudiantes, de diversas carreras y con distinto tipo de discapacidad. Dentro del estudio, aparecen como relevantes los facilitadores vinculados al entorno, referente a ayudas técnicas, familia y red social, y por otra parte, las características personales de los estudiantes, como por ejemplo la capacidad de resiliencia que les permite sobreponerse y responder con estrategias personales a los desafíos y barreras existentes.

Por lo anterior, aparecen necesidades que invitan a potenciar el cambio de paradigma de la inclusión en el ámbito educativo, que contemple un equilibrio real entre considerar los requerimientos especiales para la equidad y a su vez fomentar el trato igualitario que promueva la dignidad de las personas con discapacidad.

PALABRAS CLAVE: discapacidad, educación superior, justicia ocupacional, resiliencia, inclusión.

a Universidad de Magallanes, Avenida Bulnes 01855, Punta Arenas, Chile. oskarina.palma@umag.cl; ximena.soto@umag.cl; camila.barria.to@gmail.com; xluceroaguayo@gmail.com; danimella@gmail.com; santana.yayi@gmail.com; enrique.o.seguel@ hotmail.com 


\title{
AN QUALITATIVE STUDY OF THE ADAPTATION PROCESS AND \\ INCLUSION OF A GROUP OF STUDENTS WITH DISABILITIES FROM HIGHER EDUCATION AT UNIVERSIDAD DE MAGALLANES.
}

\begin{abstract}
According to the Science of Occupation and Occupational Justice, participation and inclusion within significative occupations is basic for the development of people and communities. However, this inclusion is not always favored in every public space. An important development took place within education, principally for primary levels forming the basis for potential projects like that of School Integration which offers a place for students with discapacities. These projects were not included at Superior Education, which is reason why students need to produce their own strategies to be included. The reason is that physical as well as social environments are not prepared to answer to the special necessities of students with different discapacities as a way of access to real and equitative education.

The goal of this research is to obtain antecedents about the inclusion and adaptation processes of a group of young students with discapacities at the Universidad de Magallanes with the aim to contribute to these policies. For that reason a qualitative methodology was used using the experience of 15 students from different careers and different discapacities. Factors related with the social environment, like technical help, families and social connections appear as relevant; on the other hand the student's personal characteristics, like their capacity for resilience is what allows them to overcome and answer with personal strategies to the existing challenges and barriers.

For all these reasons, some necessities are evident, requiring a change in paradigm concerning the inclusion of these students in the educational field, by providing an effective balance through considering the special requirements for equity and promoting the equal treatment in which the dignity of the people with disabilities is ensured.
\end{abstract}

KEY WORDS: disabilities, higher education, occupation justice, resiliency, inclusion.

\section{PLANTEAMIENTO DEL PROBLEMA}

En las últimas décadas y considerando los avances en el desarrollo de temáticas principalmente vinculadas con los derechos humanos y justicia social, se ha observado como a su vez, han evolucionado los conceptos de discapacidad y rehabilitación, estableciéndose actualmente una búsqueda de mayor apertura de la sociedad a aceptar las diferencias como parte de la naturaleza humana y también una búsqueda de igualdad y equiparación de oportunidades para el acceso real a la participación plena de las personas con discapacidad en diversos ámbitos de las ocupaciones humanas.

La evolución del concepto de discapacidad, ha sufrido grandes cambios a lo largo de la historia. Durante los últimos años, hemos visto como se ha ido abandonando una perspectiva paternalista y asistencial de la discapacidad, que miraba a la persona como un ser "dependiente y necesitado", hacia un nuevo enfoque, que contempla a la persona en situación de discapacidad como un individuo con habilidades, recursos y potencialidades. Esta evolución se ha visto acompañada de avances paralelos, tanto en el tratamiento médico, como en la inserción social de este colectivo (Fundación Prevent, 2010)

En la década de 1970 se pone en marcha la CIDDM (Clasificación internacional de deficiencias, discapacidades y minusvalías) la cual fue publicada en 1980 por la OMS, esta fue criticada debido a que realizaba un abordaje negativo centrado en las deficiencias, los enfoques sociales y contextuales eran escasos y se centraba en la discapacidad como un hecho individual y no universal.

A comienzo del siglo XXI, específicamente en el año 2001, se aprueba la CIF (clasificación internacional del funcionamiento, de la discapacidad y de la salud) la cual es el 
resultado del proceso de revisión de la CIDDM en 1993. La CIF define la discapacidad como un término genérico que abarca deficiencias, limitaciones de la actividad y restricciones a la participación. Se entiende por discapacidad la interacción entre las personas que padecen alguna enfermedad o dfeiciencia (por ejemplo; parálisis cerebral, síndrome de Down y déficit sensorial) y factores personales y ambientales (por ejemplo; actitudes negativas, transporte o edificios públicos inaccesibles y un apoyo social limitado) (Minguijón et al 2005).

Es así, como las actuales concepciones de discapacidad, ponen el acento en la responsabilidad de los otros y la sociedad en términos de establecer barreras o no proporcionar las oportunidades para la participación plena, conllevando esto como resultado la aparición de "discapacidad", para alguien que en otras condiciones de facilitación, no tendría impedimento para la realización de sus actividades.

Hoy entonces, entendemos la discapacidad no como parte del sujeto que posee alguna enfermedad o deficiencia, sino que el problema está puesto en la sociedad, es ésta la que no se encuentra preparada para hacer accesible la participación a todos sus ciudadanos.

A partir de este nuevo paradigma que busca la participación social en los diferentes contextos en los cuales nos desenvolvemos, nos preguntamos ¿Estamos o no preparados, desde el ámbito de la educación superior, para entender nuestra responsabilidad social con el tema de la discapacidad? y más aún ¿Está preparada la sociedad chilena, considerando los empleadores y trabajadores, para incluir en igualdad de condiciones a una persona con discapacidad en puestos laborales, acordes a su nivel de formación profesional?.

Considerando las estadísticas, el informe mundial sobre la discapacidad, señala que se estima que más de mil millones de personas viven con algún tipo de discapacidad; o sea, alrededor del $15 \%$ de la población mundial, según las estimaciones de la población mundial en 2010 (OMS, 2011). A nivel latinoamericano, las cifras sobre discapacidad según el Banco Mundial, hablan que en 2009 había al menos 50 millones de personas con algún tipo de discapacidad en
América Latina y el Caribe (Stang-Alva, 2011). Según Primer estudio nacional de la discapacidad ENDISC (MIDEPLAN, 2004), en nuestro país el $12.9 \%$ de los chilenos vivía con algún grado de discapacidad, lo que supone más de 2.000.000 de personas, es decir, 13 de cada 100 o una de cada ocho personas. Los datos recientemente obtenidos con la segunda encuesta nacional de la discapacidad, ENDISC 2015, son aún más preocupantes ya que refieren que el $20 \%$ de la población nacional presenta algún grado de discapacidad, a nivel regional esta cifre se eleva a 24,2 \% para la región de Magallanes y Antártica chilena (MIDEPLAN, 2015).

A nivel mundial y más aún a nivel nacional, las estadísticas de personas con discapacidad que logran llegar a la educación superior son muy bajas, de éstas, quienes logran concluir sus estudios con éxito, requieren de mucho esfuerzo y perseverancia para superar los diversos obstáculos y barreras que nuestra sociedad le imponen para personas con diferencias que escapan al "molde estándar" preestablecido.

Culturalmente, aunque han existido cambios, mayor apertura y a su vez legislación que lo respalda, parece aún insuficiente la actitud que tiene la sociedad en general, en cuanto a la capacidad de empatía, solidaridad y respeto por el otro, independiente de sus diferencias, por ejemplo, muchas veces el poder comunicarnos y entendernos con personas que sufran de algún tipo de discapacidad, puede tomar más tiempo que el habitual y debemos poner más atención y dedicación; o en el caso de discapacidad física, tal vez, debemos ser más pacientes o cautelosos, porque el desplazamiento y desarrollo de una actividad puede tomar más tiempo a comparación de un ciudadano promedio. Una vez "concedidas" estás consideraciones nos damos cuenta que podemos validar al otro como un legítimo merecedor de todo nuestro respeto y admiración.

Creemos que el acceso muy lentamente creciente de personas con discapacidad a la educación superior, marcará un hito interesante en los próximos años, para el posicionamiento de personas con discapacidad en nuestra sociedad, si es que realmente existe una apertura en las posibilidades laborales y no se discrimina en 
cuanto a las contrataciones y acceso a los puestos de trabajo y ascensos de acuerdo a habilidades y capacidades sin otras consideraciones, es decir, siendo validados y mirados desde sus capacidades y no desde sus discapacidades. "Las personas con más educación, tienen mayores oportunidades, asegura la movilidad social y se constituye en un espacio para el encuentro social" (Filmus, 2005).

Por otra parte, hablamos de inclusión e igualdad al momento en que la sociedad no hace un énfasis en las características de la persona, sino más bien, la ve como un todo sin diferencia alguna. Sin embargo, en la actualidad esta inclusión e igualdad no se experimenta completamente, ya que no hay un compromiso ni una acción inclusiva que la propicie. Por lo tanto, se habla de exclusión social, la que provoca una situación de discriminación y marginación, contraria a los conceptos antes mencionados (Ferreira \& Díaz, 2007).

A raíz de esto, suponemos que quienes excluyen son las mismas personas que componen la sociedad, puesto que estas son las que generan las barreras físicas, sociales, arquitectónicas, culturales, etc. pensando sólo en un diseño único y dominante, no considerando la diversidad de personas existentes.

En cuanto a los ambientes y espacios físicos, estos en general no contemplan o no consideran que todas las personas con su diversidad o en este caso discapacidad, puedan tener realmente acceso en igualdad de condiciones, para De Rojas y Santos (2005) la accesibilidad es la "(...) característica que permite el uso y disfrute de un entorno a cualquier persona, con independencia de su condición física, sensorial o intelectual". Juncà (2005) explica que el padre del concepto de accesibilidad universal es Ronald L. Mace, (1985, citado en Junca, 2005), quien propuso los principios del término, este (...) consiste en planear, proyectar, construir, rehabilitar y conservar el entorno de modo que tenga en cuenta la envolvente de necesidades y requerimientos de cualquier persona, sea cual sea su edad, circunstancia o capacidades.

Un entorno acorde con los principios de la accesibilidad universal (...) será un entorno que facilite el desenvolvimiento y uso del mismo por cualquier persona, desde unas características de comodidad, seguridad y autonomía personal.

De Asís y Palacios (2007) explican que la "(...) accesibilidad ha dejado de ser abordada desde la toma de medidas especiales, dentro de un proceso de rehabilitación individual de un sujeto, pasando a serlo desde la búsqueda de respuestas adecuadas, en condiciones de igualdad, a las necesidades de todas las personas" (Salas, 2013).

En el ámbito de la educación, vemos como en general las instituciones no siempre resguardan las consideraciones de diseño universal, existiendo amplias falencias en proteger el acceso $y$ participación de personas con algún tipo de discapacidad, comprendiéndose en este contexto estudiantes, profesores y familias o visitantes del establecimiento.

Con un cambio de paradigma podríamos dar un gran avance, si al diseñar y construir se considerasen los ocho principios del diseño universal. Según Víquez (citado en Salas, 2013), estos principios, fundamentales e ineludibles, son: el uso equitativo; la flexibilidad en el uso; la información perceptible; el tamaño y el espacio para la aproximación y uso; el uso simple e intuitivo: ser altamente seguras; implicar bajo esfuerzo físico, especialmente para quienes requieren de aditamentos tales como, silla de ruedas o el apoyo del bastón, y poseer dimensiones apropiadas. Del mismo modo Guillamón (2003, citado en Salas, 2013) propone la calidad del diseño, la funcionalidad, la seguridad, la vida independiente, la comodidad y la innovación como rasgos de un diseño universal (Salas, 2013).

Además de las barreras arquitectónicas, que limitan físicamente el acceso a la participación e inclusión en las diversas ocupaciones, las personas con discapacidad deben superar barreras sociales y un acumulo de mitos, discriminación y prejuicios en torno a sus capacidades y posibilidades de éxito en las diversas tareas que emprenden, es así, como desde la sociología y sicología se presenta como relevante el entorno familiar y las características personales de los sujetos, para superar sus desafíos y ponerse nuevas metas. Hay quienes plantean que las personas con discapacidad $\mathrm{u}$ otros grupos de personas que viven situaciones traumáticas o de discriminación, pueden desarrollar de mejor manera la capacidad de 
sobreponerse a las adversidades, este concepto se conoce como resiliencia (Piaggio, 2009).

La resiliencia designa la capacidad humana de superar traumas y heridas. Las experiencias de huérfanos, niños maltratados o abandonados, víctimas de guerras o catástrofes naturales, han permitido constatar que las personas no quedan encadenadas a los traumas toda la vida, sino que cuentan con un antídoto: la resiliencia. No es una receta de felicidad, sino una actitud vital positiva que estimula a reparar daños sufridos, convirtiéndolos, a veces, hasta en obras de arte. Pero la resiliencia difícilmente puede brotar de la soledad, la confianza y solidaridad de otros, ya sean amigos, maestros o tutores, es una de las condiciones para que cualquier ser humano pueda recuperar la confianza en sí mismo y su capacidad de afecto (Cyrulnik, 2003).

Estamos en presencia entonces, de una doble problemática, en la que por un lado la sociedad debe asumir y aceptar las diferencias entre sus integrantes, incluyendo a las personas en situación de discapacidad y desarrollar acciones para que estas sean incluidas $y$, por otro lado, estos deben aceptar y sobreponerse a su situación para poder reducir al mínimo sus limitaciones de participación. Entendiéndose que las personas se encuentran incluidas dentro de un contexto cambiante. Los ambientes van cambiando continuamente, y a medida que cambian, cambia también el comportamiento necesario para lograr un objetivo (Crepeau et al. 2005) por lo tanto, también las personas deben desarrollar las capacidades para desenvolverse socialmente y lograr sus metas.

En la actualidad, se han desarrollado derechos especiales para personas con discapacidad, tanto en el ámbito de la salud, el acceso a la educación, políticas claras en torno al trabajo, transporte accesible y sin discriminación, más participación ciudadana, entre otras áreas vitales. Esto es el resultado de un trabajo que hace décadas se viene desarrollando a nivel internacional y que visibiliza sus derechos, ubicándolos como una prioridad fundamental para los Estados.

En nuestro país, en el camino para reconocer estos derechos especiales, según la Fundación Nacional de Discapacitados, en el año 2011, Chile ratificó la convención interamericana para la eliminación de todas las formas de discriminación contra las personas con discapacidad y en el año 2008 también firma como estado parte la convención de las Naciones Unidas sobre los derechos de las personas con discapacidad y su protocolo facultativo. Pese a la firma de estos tratados internacionales, así como convenios de protección laboral de la Organización Internacional del Trabajo (OIT), entre otros, la situación de las personas con discapacidad en Chile es particularmente adversa, pues experimentan cotidianamente barreras para el disfrute y goce de sus derechos, sobre todo en materias tan sensibles como salud, educación, trabajo y transporte.

Además, en 1994 fue promulgada la ley 19.284, que fue la primera regulación en el país sobre los derechos de las personas en situación de discapacidad. En esta se definió persona con discapacidad a toda aquella que, como consecuencia de una o más deficiencias físicas, psíquicas o sensoriales, congénitas o adquiridas, previsiblemente de carácter permanente y con independencia de la causa que las hubiera originado, vea obstaculizada, en al menos un tercio, su capacidad educativa, laboral o de integración social (Ley 19.284, 1994). Creando, además, el Fondo Nacional de la Discapacidad (FONADIS) para la administración de recursos estatales en favor de personas con esa condición y el registro nacional de la discapacidad, a través del cual se reúnen y mantienen los antecedentes de personas que hayan sido declaradas "discapacitadas" por las respectivas Comisiones de Medicina Preventiva e Invalidez (COMPIN) y que hayan expresado su voluntad de ser inscritas.

Luego, en el año 2005 ingresa al congreso como mensaje del ejecutivo, un nuevo proyecto de ley que proponía principalmente las siguientes modificaciones:

- La redefinición de persona con discapacidad.

- La fijación de principios rectores para una correcta aplicación de la ley.

- Una sustitución completa de la reglamentación relativa a prevención y rehabilitación.

- El impulso a una mejor equiparación de oportunidades. 
- Una completa modernización de FONADIS.

Esta nueva mirada, se refiere al importante cambio de enfoque rechazando las prácticas discriminatorias, considerando la discapacidad como una cuestión de derechos humanos y enfocando el centro del problema ya no en la persona y sus carencias, sino en su interacción con el entorno y las dificultades que éste le presenta para participar en forma plena (Reforma de Leyes, 2008), representa el avance que se ha producido a nivel mundial, del que Chile también ha sido parte, suscribiéndose a los tratados internacionales de Derechos Humanos.

Posteriormente, el 10 de Febrero del año 2010 se promulgó la ley 20.422, que modifica el concepto de fondo a servicio, englobando todas las políticas públicas en relación a temas de discapacidad en el Servicio Nacional de Discapacidad (SENADIS) el cual, define a la persona con discapacidad como aquella persona que teniendo una o más deficiencias físicas, mentales, sea por causa psíquica o intelectual, o sensoriales de carácter temporal o permanente, al interactuar con diversas barreras presentes en el entorno, ve impedida o restringida su participación plena y efectiva en la sociedad, en igualdad de condiciones con las demás.

En el ámbito de la educación, se han visto algunos avances aunque resultan insuficientes. En el año 2003 surge el Programa de integración escolar en Chile, Arreaza (2009) explica que en este modelo, se adscribe a la persona diversa al grupo normalizado (...). El citado programa se recoge en una adaptación curricular y se organiza la respuesta, individual o en grupos reducidos, durante un tiempo variable, en un espacio a determinar, fuera o dentro del aula, con los recursos específicos, sin embargo, esto da a entender también que es el estudiante el que presenta el problema, puesto que necesita de mayor implementación y adaptaciones especiales, no comprendiendo que somos nosotros los que debemos generar un ambiente universal para la diversidad de personas. Es por esto, que este programa no suple lo que las personas con discapacidad necesitan, que es un acceso a la educación de forma inclusiva y con igualdad de oportunidades.

Según el documento de discusión de la
Unesco 2007, una educación de calidad para todos, un asunto de derechos humanos, desde la perspectiva de la equidad, es preciso equilibrar los principios de igualdad (lo común) y diferenciación (lo diverso). Es una obligación de los sistemas educativos asegurar la equidad en una triple dimensión: en el acceso, en los procesos y en los resultados. La educación debe tratar de forma diferenciada lo que es desigual en el origen, para llegar a resultados de aprendizaje equiparables y no reproducir las desigualdades presentes en la sociedad (UNESCO 2007).

En relación al acceso a la educación, según cifras del SENADIS 2013, sólo uno de cada quince estudiantes con discapacidad logra acceder a la educación superior, de acuerdo a ENDISC, MIDEPLAN 2004, un 6,6\% de las personas con discapacidad accede a la educación superior (institutos, universidad y centros de educación técnico profesional), de los cuales sólo un $2.66 \%$ completa su formación, personas con discapacidades visuales y físicas, son las que más acceden, siendo menor proporción quienes presentan discapacidad intelectual. De las personas con discapacidad que han accedido a la educación superior, el $60 \%$ no ha completado sus estudios. Al contrario, dos de cada cinco personas con discapacidad que han accedido a alguna instancia de Educación Superior, han terminado sus estudios (SENADIS, 2004).

Esto resulta preocupante, considerando que existe legislación que apoya los proceso de inclusión escolar en todos los niveles, como se indica en la Convención sobre los derechos de las personas con discapacidad (ONU, 2006), donde se plantea a nivel de educación superior en su artículo $n^{\circ} 24$, que los estados parte: "asegurarán un sistema de educación inclusivo en todos los niveles, así como la enseñanza a lo largo de la vida..." "que las personas con discapacidad tengan acceso general a la educación superior..." y que los estados partes "asegurarán que se realicen ajustes razonables para las personas con discapacidad".

A nivel nacional, se establece en el artículo $n^{\circ} 39$ de la ley de discapacidad 20.244 que el Ministerio de Educación, cautelará la participación de las personas con discapacidad en los programas relacionados con el aprendizaje, desarrollo cultural y el perfeccionamiento. Las instituciones 
de educación superior deberán contar con mecanismos que faciliten el acceso de las personas con discapacidad, así como adaptar los materiales de estudio y medios de enseñanza para que dichas personas puedan cursar las diferentes carreras (ley 20.422).

Por otro lado y considerando las enormes brechas que existen para lograr una situación de igualdad y equidad, especialmente en el ámbito de acceso y permanencia en la educación superior, el Departamento de Educación de SENADIS a nivel nacional, ha implementado algunas acciones con el fin de contribuir al sistema educacional en respuestas educativas pertinentes y de calidad a los estudiantes con necesidades educativas especiales $e$ instalar competencias técnicas y transversales en los distintos ámbitos educacionales para la inclusión educativa, estas son:

Creación de la red de educación superior inclusiva: Esta red está instalada en 11 regiones del país, incluida la región de Magallanes y Antártica Chilena. En Punta Arenas se constituyó el 28 de junio del 2012 y está conformada por el Instituto Santo Tomás, la Universidad Tecnológica INACAP y la Universidad de Magallanes. $\mathrm{Su}$ objetivo es articular una Red nacional de trabajo que permita fortalecer el desarrollo de la Educación Superior, en temáticas vinculadas a la inclusión de personas con discapacidad en el nivel terciario y producir conocimientos que permitan optimizar la integración e inclusión educativa en los distintos niveles y modalidades educativas.

- Encuentros regionales de educación superior inclusiva, realizados en diferentes instituciones de educación superior a lo largo del país, buscan fortalecer el desarrollo de la educación superior en temáticas vinculadas a la inclusión educativa de las personas con discapacidad y atención a la diversidad, como estrategia que favorezca a toda la comunidad educativa.

- Plan de continuidad para estudiantes con discapacidad en educación superior. Está dirigido a estudiantes con discapacidad auditiva y física, que se hayan adjudicado proyectos individuales del Concurso nacional de proyectos durante el año 2011; estudiantes con discapacidad auditiva y física, que hayan sido beneficiarios de proyectos institucionales del fondo nacional de proyectos 2011 y aquellos estudiantes que durante el año 2011, también fueron beneficiarios de convenios de transferencia directa de recursos, pertenecientes al Área de Educación del SENADIS.

La Universidad de Magallanes, plantea dentro de su visión y misión su compromiso social por la inclusión de los grupos más vulnerables de nuestra región, en relación al acceso a la educación superior, es por esto, que desde el año 2001, siendo pionera a nivel nacional, ha proporcionado una beca interna, otorgada desde la Dirección de Asuntos Estudiantiles (DAE), para el ingreso de estudiantes con discapacidad a las carreras de la institución. Desde dicho año, han ingresado a la universidad estudiantes con distintas discapacidades, la mayoría de ellos ha logrado concluir con éxito sus procesos académicos, egresando de la universidad con su título profesional; en este estudio nos interesa conocer, por una parte, cómo fue su proceso al interior de la universidad en relación a sus logros y dificultades, y también, posterior a esto, como ha sido su proceso de inclusión social y laboral, reconocer aspectos de la idiosincrasia regional en relación a la aceptación y apertura a la discapacidad que existe en la región, en mira a aquellos factores que debemos considerar para facilitar el cambio cultural y la real inclusión de las personas con discapacidad en nuestro país.

Conocer el proceso personal y social, con el cual han debido experimentar las personas con discapacidad en el ámbito de la educación superior y posteriormente en el ámbito laboral, nos dará luces de aquellos aspectos que como sociedad debemos trabajar para hacer de nuestro entorno un espacio más empático, justo y equitativo, donde primen valores como la justicia, y específicamente la justicia ocupacional en que todas las personas puedan acceder a desarrollarse, a estudiar y trabajar en los ámbitos donde sus intereses y habilidades les permitan una vida plena y gratificante, construyendo una comunidad más armoniosa e inclusiva.

Para contribuir a aumentar el conocimiento 
en esta área, nos hemos propuesto los siguientes objetivos en nuestra investigación:

1. Identificar los principales elementos, presentes y ausentes en el proceso de inclusión, a partir de las experiencias de los estudiantes de la Universidad de Magallanes.

2. Aportar a las políticas de inclusión de la Universidad de Magallanes.

\section{MARCO TEÓRICO}

Para el presente estudio, hemos considerado el análisis de nuestros resultados a la luz de algunos modelos y teorías provenientes principalmente del área de las ciencias sociales y de la salud y en específico desde la mirada de la ocupación y la terapia ocupacional. Los aspectos teóricos que vamos a revisar y consideramos fundamentales reconocer, surgen de nuestra mirada desde la ocupación, considerando el ingreso a la educación superior por parte de los estudiantes con discapacidad, una motivación que presenta un significado particular desde su individualidad (ocupación significativa, desde la ciencia de la ocupación) y que le genera diversas formas de movilización de recursos personales (resiliencia) y del entorno (modelos ecológicos de terapia ocupacional, teoría del constructivismo) para lograr sus objetivos, dentro de los cuales se enfoca como un tema de derechos humanos la inclusión y participación en el ámbito estudiantil y laboral (justicia ocupacional), que de acuerdo a diversas condiciones, principalmente sistémicas, se logra con mayor o menor éxito.

\section{Ciencia de la ocupación}

La ciencia de la ocupación deriva de la terapia ocupacional y busca aumentar el conocimiento acerca del ser humano como ser ocupacional, el cómo y por qué las personas nos involucramos en ocupaciones que nos resultan significativas y en las cuales encontramos sentido a nuestras vidas. Esta se fundó sobre las ciencias sociales interdisciplinarias y sigue manteniendo interrelaciones con algunas de estas disciplinas, que incluyen la sociología, la antropología, la filosofía y la psicología.

La ciencia de la ocupación, ha sido definida en el libro terapia ocupacional de Willard y Spackman
(2011), como una ciencia básica dedicada al estudio del ser humano como ser ocupacional (Yerxa, 1993) y, asimismo, como el estudio riguroso de los seres humanos como seres ocupacional (Wilcock, 1998). Esta ciencia se ocupa de la centralidad del compromiso en las ocupaciones y en la vida humana, sobre todo en la medida en que se relacionan con la salud, el bienestar y la participación social. Sin embargo el núcleo de la ciencia de la ocupación no es solo la actividad propiamente tal, sino también los actores sociales que participan en actividades dentro de las particularidades sociales, culturales e históricas del mundo en que viven; esencialmente, como viven y aprenden las personas en la vida cotidiana; las relaciones entre actividad, participación y salud; y de qué modo los compromisos sociales y las estructuras sociales proporcionan y limitan la salud, la participación, la calidad de vida y la experiencia humana. Según esta perspectiva, se podría considerar que la ciencia ocupacional se encarga de las distintas formas en las cuales las personas se ocupan como seres humanos y el impacto que este compromiso tiene sobre los cuerpos, las personalidades, las comunidades y el mundo. (Willard \& Spackman, 2011).

\section{Justicia ocupacional}

Si entendemos al ser humano como un ser ocupacional que se motiva y moviliza para lograr involucrarse en diversas ocupaciones en las cuales encuentra sentido, que espacios reales se abren para la participación de todos en las actividades que les son significativas, es que existen algunas ocupaciones que son privativas de ciertos grupos de personas y por otra parte existen ocupaciones que son más "importantes" que otras, de acuerdo a la comprensión de los conceptos de igualdad y equidad en el acceso a la participación y la inclusión consideramos que dentro del concepto de justicia, también debe considerarse la justicia en torno a la participación en ocupaciones, la justicia ocupacional (occupational justice), concepto que surge de los trabajos de Wilcock y Townsend (2004), centrados en las relaciones entre la ocupación y la salud y sus determinantes sociales, políticos y culturales, considerados estos últimos en términos de justicia. (Moruno \& Fernández, 2012). 
La originalidad del concepto de justicia ocupacional reside en cambiar el foco de atención de lo individual a lo colectivo o comunitario; es decir, en caracterizar hechos que, aunque tienen efectos individuales, hacen referencia a grupos sociales o comunidades, causados por fuerzas externas al individuo, socialmente construidas sobre la base de valores culturales, que crean exclusión y conducen a situaciones de privación, alienación e injusticia ocupacional.

El concepto de justicia ocupacional (Towsand \& Wolcock, 2004) aparece para completar y extender el entendimiento de la justicia social. Una perspectiva ocupacional, creemos, ilumina nuevas perspectivas e insigths sobre la injusticia, particularmente relacionadas con la participación en ocupaciones.

Los otros conceptos asociados a la justicia ocupacional, son el de privación y el de alienación ocupacional. El concepto de privación ocupacional (occupational deprivation) aparece en la literatura de terapia ocupacional en los trabajos de Whiteford (1995, 1997, citado por Moruno \& Fernández, 2012). En ellos, estudia los efectos de las limitaciones para implicarse y desarrollar ocupaciones significativas en la población carcelaria con necesidades especiales (historia de enfermedad mental, borderline $y$ otras). Se utiliza para describir una situación que genera limitaciones en el desempeño de actividades, debidas a factores situacionales, del contexto inmediato del individuo relacionados con la política carcelaria, y que impide el uso de herramientas, altera los patrones de uso del tiempo y las rutinas y se asocia a diversos efectos tales como: desorientación, pérdida del sentimiento de eficacia, ratio elevada de suicidio, trastornos del sueño y dificultades para la adquisición de destrezas adaptativas para lograr la integración en comunidad. La autora subraya que el estado de privación no es consecuencia de limitaciones inherentes al individuo, sino debido a factores externos, fuerzas fuera de su control, que se prolongan en el tiempo.

No obstante, son a los escritos de Wilcock (1998) a quien debemos los primeros intentos de definición y sistematización del concepto, que aparece junto al de alienación ocupacional (occupational alienation) en el artículo: An occupational perspective of health concibe ambos como factores de riesgo para la salud y ligados al padecimiento de enfermedades. Indica que dichos factores de riesgo están determinados por valores sociales y culturales, leyes y normas, organización política y estructura económica. La privación implica la influencia de una entidad o circunstancia que impide a una persona adquirir, usar o disfrutar algo; para el caso de la privación ocupacional tales entidades o circunstancias son: "la tecnología, la división (social) del trabajo, la ausencia de oportunidades de empleo, la pobreza o el poder adquisitivo, los valores culturales, las normas o regulaciones legales locales y las limitaciones impuestas por los sistemas educativos o de servicios sociales, así como la enfermedad y la discapacidad" (Moruno \& Fernández, 2012).

\section{Teoría de resiliencia}

El término resiliency nació en la física (soltura de reacción, elasticidad), designaba la capacidad de un cuerpo para resistir un choque. Cuando pasó a las ciencias sociales, se definió como "La capacidad de triunfar, para vivir y desarrollarse positivamente, de manera socialmente aceptable, a pesar de la fatiga o de la adversidad, que suelen implicar riesgo grave de desenlace negativo". Según Cyrulnik (2003), el oxímoron es una figura retórica que consiste en reunir dos términos antinómicos, la oscura claridad. No es la ambivalencia del individuo de expresar sentimientos opuestos - amor y odio. El oxímoron se vuelve característico de una persona herida pero resistente, sufriente pero feliz de esperar a pesar de todo. Es la capacidad de ver la maravilla del dolor. La resiliencia define el resorte de los que, habiendo recibido un golpe, han podido sobrepasarlo. El oxímoron describe el mundo íntimo de esos vencedores heridos. El concepto de resiliencia, es tal vez, opuesto al concepto de riesgo, o mejor dicho complementario de él. El enfoque de resiliencia se explica por lo que se ha llamado el modelo de la resiliencia. Este muestra que las fuerzas negativas, expresadas como daños o riesgos, no encuentran a un niño inerme en el cual se determinan inevitablemente daños permanentes. Este modelo describe la existencia de verdaderos escudos protectores o factores 
de resiliencia que harán que dichas fuerzas no actúen linealmente, atenuando sus efectos y hasta transformándolos en factores de superación de una situación difícil.

Esto llevó a un cambio de enfoque, se comenzó a pensar más positivamente, ¿Qué hacer para que la gente no enferme?, ¿Por qué no se enferman, los que no se enferman?, ¿Cómo estimular los factores de resiliencia? Y surgió así la promoción en salud, que es anterior a la prevención, promover estilos de vida, a reconocer la importancia que tiene todo lo que se refiere al desarrollo integral del niño, programas que tiendan a mejorar las condiciones de vida globales de los seres humanos en vez de evitar daños específicos. De allí, que el concepto de resiliencia haya despertado gran interés para la investigación y su aplicación en distintos programas. Si bien en su origen nació de la psicología social, se ha expandido a la sociología, y a las ciencias de la educación, que es donde más se utiliza. Algunos países se están planteando toda una renovación de los programas en función de este concepto. (Rodríguez et al. 2009).

En relación con las definiciones antes mencionadas, hemos considerado relevante la capacidad de resiliencia para intentar comprender los procesos personales que han realizado y realizan los estudiantes en situación de discapacidad, para incorporarse y mantenerse en el ámbito de la educación superior $y$ posteriormente en la obtención y mantención de un trabajo remunerado.

\section{Teoría de la construcción social}

El constructivismo es una posición compartida por diferentes tendencias de la investigación psicológica y educativa. Entre ellas, se encuentran las teorías de Piaget (1952), Vygotsky (1978), Ausubel (1963), Bruner (1960) (todas citadas en Parica et al. 2005) y, aun cuando ninguno de ellos se denominó como constructivista, sus ideas y propuestas claramente ilustran las ideas de esta corriente (Parica et al. 2005)

El Constructivismo, dice Méndez (2002), es en primer lugar una epistemología, es decir, una teoría que intenta explicar cuál es la naturaleza del conocimiento humano. El constructivismo, asume que nada viene de nada. Es decir, que el conocimiento previo da nacimiento a un conocimiento nuevo.

El constructivismo social es aquel modelo basado en el constructivismo, que dicta que el conocimiento además de formarse a partir de las relaciones ambiente-yo, es la suma del factor entorno social a la ecuación. Los nuevos conocimientos se forman a partir de los propios esquemas de la persona producto de su realidad, y su comparación con los esquemas de los demás individuos que lo rodean.

El constructivismo busca ayudar a los estudiantes a internalizar, reacomodar, otransformar la información nueva. Esta transformación ocurre a través de la creación de nuevos aprendizajes y esto resulta del surgimiento de nuevas estructuras cognitivas según Brooks y Brooks (1999), que permiten enfrentarse a situaciones iguales 0 parecidas en la realidad. Todas estas ideas han sido tomadas de matices diferentes, se pueden destacar dos de los autores más importantes que han aportado al constructivismo: Piaget con el "constructivismo psicológico" y Vigotsky con el "constructivismo social" (Parica et al. 2005).

Desde otra perspectiva esta teoría alude a la construcción social de la realidad de acuerdo a Berger y Luckman (1966), quienes destacan la importancia de la interacción social y del lenguaje, en este proceso. Resulta interesante entonces analizar como los grupos e individuos construyen colectivamente la realidad y como esta construcción se trasmite y se reproduce en la sociedad.

Lo anterior aplicado al ámbito de la discapacidad, permitiría influir en la transformación social y cultural de este concepto, tanto desde el colectivo, como desde las propias personas, la "identidad" personal, en nuestra cultura, se construye en un contexto social, implica una participación y una convivencia social, y requiere de los recursos de los que este marco social nos provee. En consecuencia, en términos de identidad, la discapacidad debe ser entendida a la luz de ese marco o contexto social que determina cuál es su sentido. En palabras de Paul Abberley: La teoría tradicional (...) sitúa la fuente de la discapacidad en la deficiencia del individuo y en sus discapacidades personales. En contraposición, el modelo social entiende 
la discapacidad como el resultado del fracaso de la sociedad al adaptarse a las necesidades de las personas discapacitadas (Abberley, 1998, citado en Ferreira, 2008)

\section{Modelos ecológicos}

En la década de 1990, tres grupos de terapeutas ocupacionales que trabajaban de forma independiente, crearon modelos separados que destacaban la importancia de considerar el entorno en la práctica de la terapia ocupacional. Los tres modelos, el modelo de la ecología del desempeño humano (Dunn et al. 1994), el modelo de persona, entorno y desempeño ocupacional (Christiansen \& Baum, 1997) y el modelo de persona, entorno y ocupación (Law et al. 1996) (citados en Willard \& Spackman, 2011) comparten muchas similitudes y algunas diferencias. Los tres modelos dinámicos consideran el desempeño ocupacional como el resultado primario de interés para los terapeutas ocupacionales. Sin embargo, los que desarrollaron los modelos tenían más intención de promover la importancia del entorno. (Willard \& Spackman, 2011).

Los modelos ecológicos se basan en la triada de persona, entorno, ocupación/tarea, la interrelación de estos elementos tiene como finalidad un óptimo desempeño ocupacional. La persona, incluye sus valores $e$ intereses, habilidades, capacidades y experiencias de vidas. El entorno es donde tiene lugar el desempeño ocupacional y consiste en componentes físicos, culturas y sociales. La ocupación son actividades significativas y dirigidas a objetivos que se extienden típicamente en el tiempo y la tarea se define como las representaciones objetivas de todas las actividades posibles disponibles en el universo. Por último, los modelos describen que el desempeño ocupacional es el resultado que se asocia con la confluencia de los factores de persona, entorno y ocupación/tarea. El grado en el cual es posible el desempeño ocupacional depende de la bondad de ajuste de estos factores.

Desde esta perspectiva la adaptación y consecuente satisfacción con su participación en actividades contempla por una parte necesidades y características de la persona, las características particulares de la ocupación en la que se está involucrado y en igual medida las características del ambiente o entorno en que estas se realizan.

\section{MARCO METODOLÓGICO}

La presente investigación es de carácter cualitativo, el cual se refiere en su más amplio sentido a la investigación que produce datos descriptivos: las propias palabras de las personas, habladas o escritas y ...la conducta observable... (Taylor \& Bogdan, 1987). La investigación cualitativa es la comprensión, centrando la indagación en los hechos. Desde la investigación cualitativa se pretende la comprensión de las complejas interrelaciones que se dan en la realidad.

Por otro lado, el diseño de esta investigación es de tipo exploratorio, entendiéndose básicamente cuando el tema ha sido poco estudiado o no ha sido estudiado antes o bien cuando se aplica en un contexto distinto al ámbito qué se aplicó previamente. En la presente investigación, se conocerán las visiones de las personas con discapacidad que cursan la educación superior de una entidad académica en particular, de manera que exploraremos en base a sus experiencias los procesos por los cuales se enfrentan durante este periodo y al momento de entrar al mundo laboral. Contando con un universo de hombres y mujeres con discapacidad, pertenecientes a la universidad de Magallanes.

Respecto del colectivo de investigación, se apuntan los siguientes criterios de inclusión:

- Jóvenes estudiantes y egresados con algún tipo de discapacidad.

- Pertenecientes a la Universidad de Magallanes de la ciudad de Punta Arenas.

- Beneficiarios con la beca de discapacidad que entrega la institución, a partir del año 2001 hasta el 2013.

La participación de los estudiantes en el estudio fue voluntaria e informada y se concertó través de un consentimiento informado, el cual se fue leído y firmado por los participantes al inicio del proceso.

En este estudio, se utilizaron los registros, proporcionados por la Dirección de Asuntos Estudiantiles (DAE), referentes a los estudiantes con discapacidad que han obtenido la beca de 
discapacidad de la Universidad de Magallanes.

Para la recolección de información de las experiencias vividas, se utilizó la entrevista semi-estructurada, con la cual se buscó recoger información desde los mismos protagonistas.

Para las entrevistas, el investigador previamente lleva a cabo un trabajo de planificación de la misma, elaborando un guion que determinó aquella información que quería obtener. Las preguntas que se realizaron fueron abiertas $y$ permitiendo al entrevistado la realización de matices en sus respuestas, lo que otorgó a las mismas de un valor añadido en torno a la información pesquisada. Durante el transcurso de la misma, se relacionaron temas y se fue construyendo un conocimiento comprensivo de la realidad del entrevistado. El investigador se buscó mantener un alto grado de atención en las respuestas del entrevistado para poder interrelacionar los temas y establecer dichas conexiones.

Por lo tanto, de acuerdo a lo recopilado mediante las entrevistas, se realizó una categorización del análisis de la información, con el fin de organizarla.Las entrevistas fueron grabadas, para posteriormente transcribir la información obtenida para el análisis.

La presente investigación, buscó responder a las preguntas sobre ¿Cómo es el proceso de inclusión para los estudiantes con discapacidad de la Universidad de Magallanes? y a ¿Cómo aportaremos para mejorar las políticas de inclusión dentro de la Universidad de Magallanes? Desde aquí, se plantean las siguientes categorías de análisis apriorísticas de la investigación (ver categorías apriorísticas en Tabla 1).

Esta categoría, será investigada sólo para aquellos sujetos del colectivo de investigación que presenten un criterio de inclusión, que indiquen que están titulados y que se encuentren insertos en el ámbito laboral (Tabla 2) y categorías emergentes (Tabla 3).

\section{ANÁLISIS ESTADÍSTICOS INSTITUCIONALES}

Para realizar la presente investigación, inicialmente se consideró un registro de 25 estudiantes con discapacidad, aportados por la Dirección de Asuntos Estudiantiles (DAE), sin embargo, sólo se lograron contactar a 15 de ellos, con los que finalmente se conformó el colectivo de investigación. Algunos antecedentes que permiten tener una perspectiva de éstos, es que se consideraron a nueve hombres y seis mujeres, que ingresaron a la Universidad de Magallanes entre los años 1993 y el 2013. Estos estudiantes, salvo uno de ellos, presentan la característica que fueron beneficiados con la beca interna para estudiantes con discapacidad de la Universidad, la que se otorga desde el año 2001.

Para ingresar a la casa de estudios, los estudiante lo hicieron por diferentes vías, como se aprecia en el siguiente gráfico, siendo la más frecuente con un $53 \%$ de los ingresos por vía PSU. Se destaca que los estudiantes que presentaron una discapacidad sensorial como ceguera total o hipoacusia severa no ingresaron a la Universidad por esta vía (Fig. 1).

En relación a los diagnósticos de los participantes del estudio, descritos por género en la Tabla 4, podemos identificar discapacidad asociada a trastornos sensoriales preferentemente en los varones, físicos mayoritario en las mujeres seguido de mentales y/o psíquicos en ambos grupos.

\section{MODO DE INGRESO}

Series1; Alumno trabajador, $1 ; 1$; $7 \%$

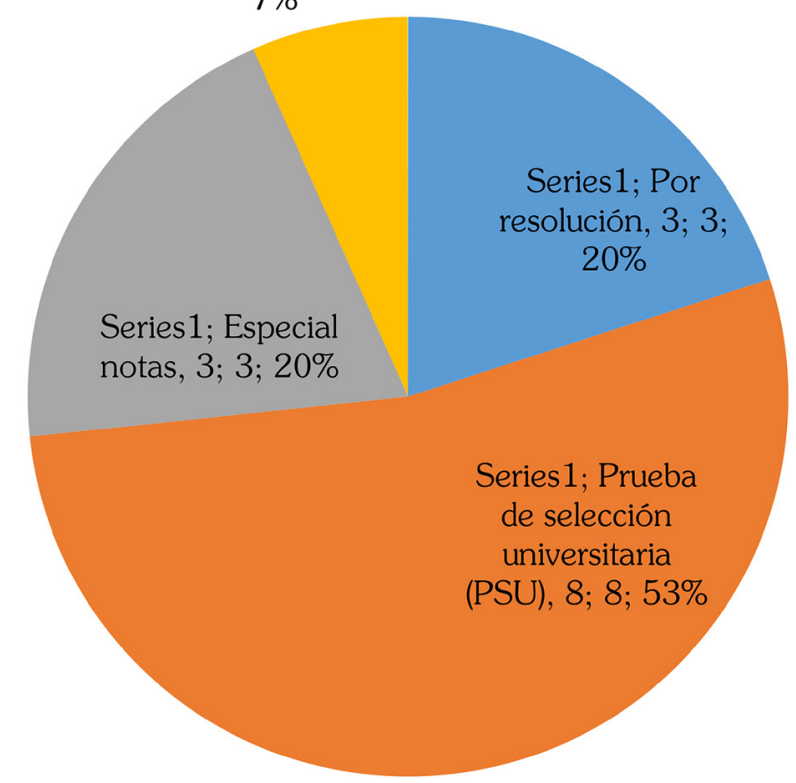

Fig. 1. Modo de ingreso a la Universidad. 
Tabla 1. Categorías apriorísticas para el colectivo de estudio.

\begin{tabular}{lll}
\hline CATEGORÍAS & SUBCATEGORÍAS & DEFINICIÓN TEÓRICA \\
\hline Relaciones & Sub1: con & Capacidad de escucha activa, \\
humanas & académicos & empatía, respeto a personas \\
& Sub2: con & muy diferentes, alteridad, \\
& estudiantes & saber ponerse en el lugar \\
& del otro y competencia para \\
& reconocer la perspectiva \\
& ajena y diferenciarla de la \\
& propia (Ander, 1986).
\end{tabular}

$\begin{array}{ll}\text { DEFINICIÓN } & \text { PREGUNTAS } \\ \text { OPERACIONAL } & \text { ORIENTADORAS }\end{array}$

\section{Los estudiantes}

entrevistados nos dicen cómo vivieron las relaciones interpersonales con sus pares y profesores en la Universidad de Magallanes. propia (Ander, 1986)

*¿Qué o quién te motivó a ingresar a la Universidad?

*Relación con sus compañeros y profesores.

*Experiencia de su paso por la universidad en sus relaciones interpersonales. *Conservas amigos que conociste dentro de la universidad?

\begin{tabular}{|c|c|c|}
\hline $\begin{array}{l}\text { Participación } \\
\text { social }\end{array}$ & $\begin{array}{l}\text { Sub1: actividades } \\
\text { culturales y de } \\
\text { recreación } \\
\text { Sub2: fiestas } \\
\text { Sub3: seminarios }\end{array}$ & $\begin{array}{l}\text { Patrones de comportamiento } \\
\text { organizados que son } \\
\text { característicos y esperados } \\
\text { de un individuo o de una } \\
\text { posición determinada dentro } \\
\text { de un sistema social (Mosey, } \\
\text { 1996, citado en AOTA, } \\
\text { 2014). }\end{array}$ \\
\hline
\end{tabular}
2014).

\begin{tabular}{ll}
\hline Rendimiento & Sub1: fortalezas \\
académico & Sub2: debilidades
\end{tabular}

Medida de las capacidades respondientes o indicativas que manifiesta, en forma estimativa, lo que una persona ha aprendido como consecuencia de un proceso de instrucción o formación (Alcaide, 2009).
Los estudiantes señalan la experiencia vividas en fiestas, seminarios o alguna actividad cultural o extra programática durante el proceso de educación superior.

Los estudiantes, nos refieren como es, o fue su rendimiento académico durante el proceso universitario, es decir, identifican las principales fortalezas y debilidades enfrentadas.
*Experiencia de su paso por la universidad en la participación social. * ¿Participaste de alguna actividad extra programática?

* ¿Cuál es la relación con su empleador y/o sus compañeros?

*¿Qué fue lo más complejo dentro de la universidad? * ¿Existía alguna evaluación especial?

* ¿Cuánto tiempo le costó sacar la carrera?

*Hubo un cambio desde la enseñanza media a la universidad?

\begin{tabular}{ll}
\hline Ambiental & Sub1: barreras \\
& arquitectónicas o de \\
& accesibilidad \\
& Sub2: facilitadores \\
& arquitectónicos
\end{tabular}

Circunstancia que ordena la situación o estado de las personas o cosas. Desde el punto de vista de la ecología, el ambiente indica condiciones exteriores dentro de las cuales se encuentra un ser vivo y que actúan sobre él. En psicología social, hace referencia a los condiciones exteriores, al actuar sobre el individuo determinan en gran parte su comportamiento. En dinámica de grupo, se suele utilizar la expresión "atmosfera grupal" para hacer referencia al "ambiente psicológico", con lo que se designa la disposición de ánimo, tono o sentido que se difunden en el grupo (Ander, 1986).
El colectivo de investigación hace referencia a los facilitadores que encontraron dentro de la institución, así como también aquellas barreras arquitectónicas que dificultaron su pleno desarrollo.
* ¿Tenía accesibilidad a la información? * ¿Te sentiste incluido dentro de la universidad? *Cuáles fueron las barreras arquitectónicas que usted identificaría en la universidad, como en el trabajo? (sugerencia). *Cuáles fueron las barreras sociales que usted identificó en la universidad, como en el trabajo? (sugerencia).

*Cuáles fueron las estrategias para sobreponerse a las dificultades? 
Tabla 2. Categorías apriorísticas para algunos del colectivo de estudio que ingresaron al mundo laboral.

\begin{tabular}{|c|c|c|c|c|}
\hline Inserción laboral & $\begin{array}{l}\text { S1: con el empleador } \\
\text { S2: con colegas }\end{array}$ & $\begin{array}{l}\text { El proceso de inserción es } \\
\text { una cadena estructurada } \\
\text { de sucesos significantes } \\
\text { en la vida del sujeto joven, } \\
\text { cuya resolución hipotética y } \\
\text { determina su proyección de } \\
\text { futuro. El proceso de inserción } \\
\text { también tiene, por tanto, una } \\
\text { vertiente psicológica, biográfica } \\
\text { e individual, sobre todo por lo } \\
\text { que implica de aprendizajes } \\
\text { negativos que pueden darse } \\
\text { de prolongarse esta secuencia } \\
\text { (Casal et al. 1989). }\end{array}$ & $\begin{array}{l}\text { Se refiere a incorporar } \\
\text { a un individuo al ámbito } \\
\text { laboral, sin importar la } \\
\text { condición de ésta. }\end{array}$ & $\begin{array}{l}{ }^{*} \text { ¿Actualmente se en- } \\
\text { cuentra trabajando? } \\
{ }^{*} \text { ¿Le costó encontrar } \\
\text { trabajo? } \\
{ }^{*} \text { ¿Se está desempeñando } \\
\text { respecto de lo que estu- } \\
\text { dió o en otra profesión? } \\
{ }^{*} \text { ¿Ha tenido dificultades } \\
\text { en el ámbito laboral? } \\
{ }^{*} \text { ¿Cuáles fueron las vías } \\
\text { de ingreso para su tra- } \\
\text { bajo? } \\
\text { * ¿Cuál es la relación con } \\
\text { su empleador? }\end{array}$ \\
\hline
\end{tabular}

Además tomando en cuenta los diagnósticos, podemos clasificarlos de acuerdo al tipo de discapacidad, en sensorial, psíquica y motora (Fig. 2).

Resulta un dato interesante, el observar que la totalidad de los entrevistados que presentan una discapacidad sensorial de tipo visual, optaron por una carrera del área de las

\section{TIPO DE DISCAPACIDAD}

cantidad; $0 ; 0 \%$

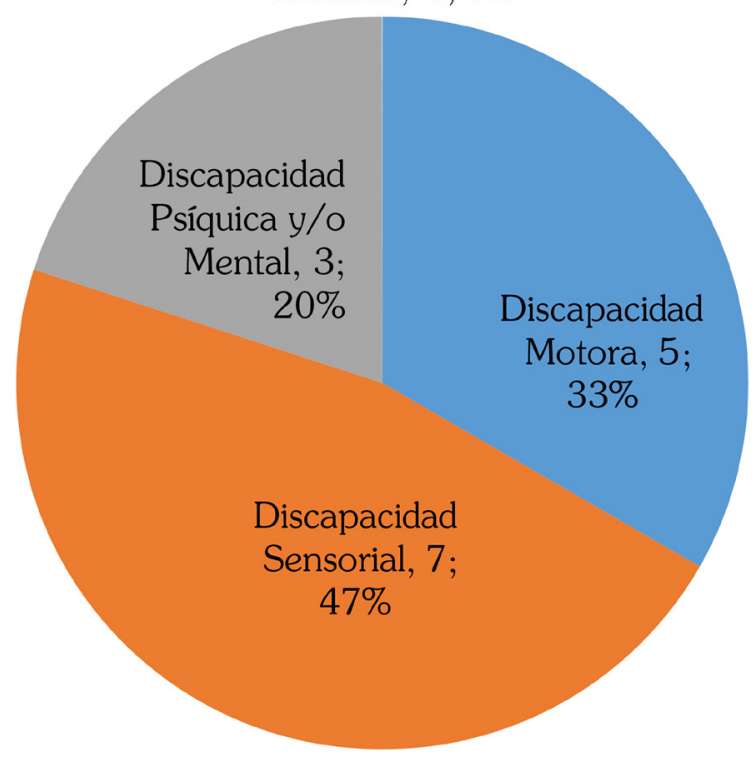

Fig. 2. Tipo de discapacidad del colectivo de estudio. ciencias sociales, aludiendo con esto a la mayor posibilidad de ejercer la profesión en que la visión no es imprescindible.

Por otro lado, en relación a la situación académica de los estudiantes que conforman el colectivo de estudio, se elaboró el siguiente gráfico (Fig. 3).

\section{SITUACIÓN ACADÉMICA}

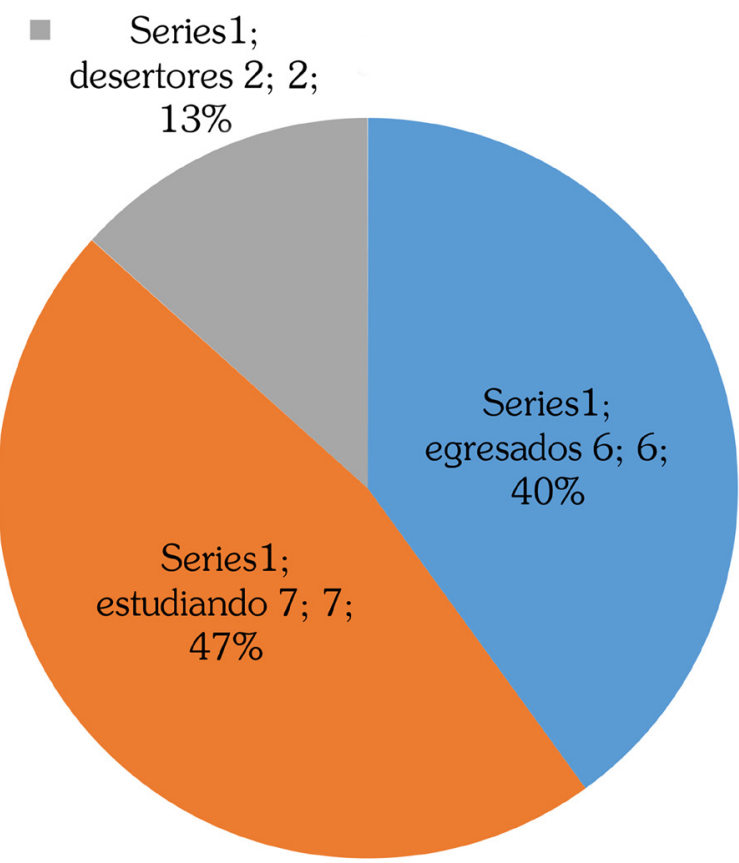

Fig. 3. Situación académica del colectivo de estudio al año 2014. 
Tabla 3. Categorías emergentes.

\begin{tabular}{|c|c|c|c|}
\hline CATEGORÍAS & SUBCATEGORÍAS & DEFINICIÓN TEÓRICA & DEFINICIÓN OPERACIONAL \\
\hline Facilitadores & $\begin{array}{l}\text { Sub 1: social } \\
\text { Sub 2: económico } \\
\text { Sub 3: arquitectónico } \\
\text { Sub 4: familiar } \\
\text { Sub 5: ayudas técnicas } \\
\text { Sub 6: ambiental } \\
\text { Sub 7: beneficios }\end{array}$ & $\begin{array}{l}\text { Los facilitadores en el estudio } \\
\text { se relacionan positivamente con } \\
\text { el compromiso, autoeficacia, } \\
\text { satisfacción y felicidad } \\
\text { relacionada con la persona. }\end{array}$ & $\begin{array}{l}\text { Facilitadores puede definirse } \\
\text { como aquellos factores que } \\
\text { facilitan, total o parcialmente, la } \\
\text { implementación de cambios. }\end{array}$ \\
\hline Discriminación. & $\begin{array}{l}\text { Sub 1: prejuicios } \\
\text { Sub 2: barreras sociales }\end{array}$ & \begin{tabular}{|l|} 
La discriminación \\
conceptualmente es una \\
conducta sistemática injusta y \\
desigual contra un grupo humano \\
determinado. Discriminar \\
consiste en privarle a un grupo \\
humano de los mismos derechos \\
que disfruten otros (Marchant, \\
2004).
\end{tabular} & $\begin{array}{l}\text { La discriminación es hacer } \\
\text { distinción en el trato por motivos } \\
\text { arbitrarios como el origen racial, } \\
\text { el sexo, el nivel socioeconómico, } \\
\text { etc. Generalmente se le da a } \\
\text { este término una connotación } \\
\text { negativa, en la medida en que } \\
\text { se trata despectivamente o se } \\
\text { perjudica a determinados grupos } \\
\text { sin mediar justificativo racional. }\end{array}$ \\
\hline $\begin{array}{l}\text { Resiliencia y estrategias } \\
\text { personales para la } \\
\text { equiparación }\end{array}$ & Sub 1: adaptación & $\begin{array}{l}\text { Capacidad del ser humano para } \\
\text { hacer frente a las adversidades de } \\
\text { la vida, superarlas e, inclusivas, } \\
\text { ser transformado por ellas } \\
\text { (Munist et al. 1998). }\end{array}$ & $\begin{array}{l}\text { La resiliencia es la capacidad del } \\
\text { ser humano de salir adelante a } \\
\text { pesar de la adversidad. }\end{array}$ \\
\hline Barreras & $\begin{array}{l}\text { Sub 1: arquitectónicas } \\
\text { Sub 2: económicas } \\
\text { Sub 3: familiar } \\
\text { Sub 4: ambiental }\end{array}$ & $\begin{array}{l}\text { Del Castillo et al. 2007, } \\
\text { identificó además de las barreras } \\
\text { relacionadas con la salud, las } \\
\text { limitaciones físicas y la edad, las } \\
\text { siguientes barreras organizativas y } \\
\text { sociales a la práctica de actividad } \\
\text { física en la vejez: deficiencias en } \\
\text { la oferta, discriminación social } \\
\text { y económica, los problemas } \\
\text { económicos, la familia, la clase } \\
\text { social, la falta de compañeros } \\
\text { para ir a las actividades, falta de } \\
\text { apoyo de la familia y amigos, las } \\
\text { responsabilidades en casa, la } \\
\text { presión social, y el precio. }\end{array}$ & $\begin{array}{l}\text { Son los obstáculos que se pueden } \\
\text { encontrar en ciertas situaciones, } \\
\text { estas pueden ser barreras } \\
\text { sociales, arquitectónicas, entre } \\
\text { otras. }\end{array}$ \\
\hline $\begin{array}{l}\text { Ocupación y proyectos } \\
\text { personales }\end{array}$ & $\begin{array}{l}\text { Sub 1: Actividades de ocio y } \\
\text { tiempo libre } \\
\text { Sub 2: Proyecciones }\end{array}$ & $\begin{array}{l}\text { Actividades diarias que } \\
\text { reflejan valores culturales } \\
\text { provee estructura de vida, y } \\
\text { significado a los individuos; } \\
\text { esas actividades se relacionan } \\
\text { con las necesidades humanas } \\
\text { de auto-cuidado, disfrute, y } \\
\text { participación en la sociedad } \\
\text { (AOTA, 2014). }\end{array}$ & $\begin{array}{l}\text { Ocupación: Actividades en donde } \\
\text { la persona que las lleva a cabo, } \\
\text { le da un significado especial y } \\
\text { tienen importancia en su vida. } \\
\text { Proyectos personales: Deseos de } \\
\text { realizar ciertas actividades a corto } \\
\text { o largo plazo. }\end{array}$ \\
\hline
\end{tabular}

Mediante este gráfico, se observa como a pesar de que es necesario implementar mayores mejoras para una completa inclusión de los estudiantes en situación de discapacidad, el número de deserciones es bajo, lo que indica que existen herramientas personales como la resiliencia, o contextuales como la familia, docentes y entorno que posibilitan la equiparación de oportunidades.

Por otro lado, es importante mencionar que los entrevistados que ya egresaron no presentaron dificultades producto de su discapacidad en relación a su rendimiento académico, logrando terminar la 
Tabla 4. Diagnósticos del colectivo en estudio.

\begin{tabular}{ll}
\hline 1. & Audición, trasplantado renal \\
Hombres & TEA, sindrome de asperger \\
& TEA, autismo \\
& Ceguera OI, catarata OD \\
& PC, hemiparesia espástica derecha \\
& Hipoacusia severa \\
& Ceguera \\
& Retinosis pigmentaria \\
& Hemiparesia izquierda \\
& Ceguera \\
& Retinosis pigmentaria y rinopatía \\
Mujeres & diabética \\
& Displasia de cadera \\
& PC mixta, hemiparesia espástica \\
& Malformación congénita en EEII Y EESS \\
& Trastorno afectivo bipolar \\
\hline
\end{tabular}

carrera que cursaban en los años correspondientes.

\section{ANÁLISIS DE CATEGORIAS}

\section{Relaciones humanas}

En lo que respecta a las relaciones humanas, estas son fundamentadas a través de los Modelos Ecológicos en Terapia Ocupacional los cuales promueven la importancia del entorno en el desempeño ocupacional de la persona; nos centraremos en el entorno social, tanto compañeros de universidad como profesores, siendo las opiniones del colectivo de investigación muy diversas. Sobre sus compañeros, algunos entrevistados expresaron que si bien existe una buena relación, no hay una cercanía con ellos; una de las entrevistadas manifestó lo siguiente: bueno, siempre tuve una relación cordial, no hice muchos amigos pero tenía una relación bastante cordial (E. 1, P. 35). Hay también una mayor aceptación, con respecto a la enseñanza básica y media a comparación con la universidad, ya que existe respeto e integración de las personas con discapacidad, a su vez, un interés en la prestación de ayuda y un apoyo práctico de estos compañeros para incluirlos dentro del contexto universitario, sobre esto, dos entrevistados comentaron lo siguiente: en la media y básica obviamente que hay discriminación así profunda, aquí (en la universidad) es como otra mentalidad, siento yo que se aceptan unos a otros (E. 15, P. 66), si no podía copiar muy bien de la pizarra a pesar de que me sentara adelante los compañeros me prestaban sus cuadernos (E. 14, P. 50). Por otro lado, surgieron opiniones referidas a la incomodidad por la interpretación por parte de los pares, de la cercanía corporal necesaria al requerir apoyo para caminar u otras actividades y la dificultad de relacionarse de forma más cercana con sus pares, en este último punto una entrevistada refiere: al no tener relación con mis pares así como salir, ir a casa de una amiga, o ir a fiestas, o de si te llamo salgamos, esa relación yo no tengo, porque me cuesta, soy tímida (E. 15, P. 22 y 24).

Por otro lado, acerca de las relaciones con los académicos de la universidad, algunos entrevistados comentan que mantenían una relación cordial con sus profesores: no mira, yo creo que no tuve ningún problema, siempre la relación con los académicos, con los profesores son buenas (E. 12, P. 22). También existía un apoyo de los académicos para que pudiesen desempeñarse de mejor manera en el ámbito universitario: el profe me pasaba guías para que me ahorrara un poco el esfuerzo de vista (E. 14, P. 50). Sin embargo, otros entrevistados comentaron que en realidad también existían dificultades con algunos profesores, ya que tenían poco conocimiento e interés de apoyarles, manifestando un entrevistado: los profesores me... me decian chuta... haber vamos a ver qué se puede hacer (con sus inasistencias reiteradas)... pero era un tema difícil, no, no comprendían del todo (E. 2, P. 21) y otros académicos no presentan ninguna consideración: mira, como primer año se me ha hecho bien difícil en verdad porque los profesores no se acostumbran, de hecho uno se tiene que acostumbrar a los profesores, entonces más que nada yo cuando hago pruebas, son en tamaño 16, entonces les mandaba una semana antes y días antes correos para que me amplien la letra ....hay algunos que se olvidan, y como que llegan con la prueba tamaño normal, "cachai" un 12, un 11 (E. 13, P. 34). Lo que hace pensar que algunos profesores tienen mucho más en cuenta la diversidad de estudiantes existentes en las aulas que otros, sin embargo, el sistema debiese incorporar un protocolo que indique como el profesor debe proceder con estudiantes que posean discapacidad, donde no quede a libre albedrio la solución de estas 
necesidades.

De acuerdo a lo anterior podemos comentar que en entorno social no siempre resulta favorable y facilitador en el ámbito académico, y que algunas veces se convierte en una barrera que dificulta en desempeño académico de manera equitativa para algunos estudiantes.

\section{Participación social}

La participación social, como categoría apriorística, se encuentra fundamentada por la teoría de la construcción social, la cual dicta que el conocimiento además de formarse a partir de las relaciones ambiente-yo, también se encuentra influenciado por el factor entorno social; viéndose reflejado esto en las opiniones vertidas por el colectivo de investigación. Como sub-categorías de la participación social se encuentran en primera instancia, la participación en actividades denominadas créditos que imparte la universidad, tanto deportivos como culturales, además las fiestas que esta misma realiza como celebración de fechas conmemorativas y por último los seminarios, jornadas y/o congresos que cada carrera realiza.

Los entrevistados en su mayoría manifestaron que su participación en actividades extra programáticas de la universidad es muy baja $y$ algunos definitivamente no participan en ninguna de ellas, según las opiniones expresadas esto se debe por una parte a la dificultad de relacionarse con sus pares y en algunos a la sensación de vulnerabilidad que sienten al encontrarse fuera de su hogar en horarios nocturnos, como se aprecia en este comentario: el hecho de estar dentro de un grupo numeroso, eso no, no me gustaba, me hacía sentir incómoda y tan tarde po, de repente se quedan tarde y asi que ahí yo como que no, no participaba, yo me restaba (E. 1, P. 59). Algunos ven dificultada también esta área de desempeño ocupacional debido a la prioridad por los estudios que les exige su entorno familiar; un entrevistado refiriéndose a este punto comenta lo siguiente yo me dedico más que nada a venir a clases y nada más, generalmente una vez que terminan las clases yo me voy a mi casa (E. 8, P. 21), a mí me gustaría formar parte de algún grupo (...) pero mi familia me dice no, tienes que estudiar no más, tienes que estudiar, o sea piensan que la universidad es para estudiar y nada más y las relaciones entre las otras personas las tengo que dejar afuera (E. 8, P. 24). Así se observa que en general, se encuentran enfocados solamente en rendir de la mejor manera en sus estudios universitarios y algunos simplemente prefieren compartir con la familia en vez de hacerlo con sus pares.

Por el contrario, dentro de nuestro colectivo de investigación existen también entrevistados que poseen una participación social más activa y una mayor sociabilización con sus pares, sin ser una dificultad el que tengan algún grado de discapacidad. Un entrevistado comenta lo siguiente: si me gusta participar, en lo que trato de participar es en todo lo que hace la mi carrera, el grupo de explora, para ayudar a los niñitos a saber qué es lo que van a querer en el futuro o las actividades como los paseos, los almuerzos, las convivencias, los juegos, y participación en staff para apoyar a la carrera, disertaciones en los colegios y bueno actividades extra programáticas todos los créditos culturales que uno tiene que tomar, los créditos deportivos (E. 14, P. 24),... y aqui en la universidad aparte como que hicimos un grupito de gimnasia entonces los viernes en la tarde o los miércoles en la tarde vamos al gimnasio y ocupamos, hacemos maquinas, pesas, abdominales, cosas así, para pasar el rato y alivianar el estrés (E. 14, P. 28).

A través de las opiniones de nuestro colectivo de investigación, nos percatamos de que muchas veces no se crean lazos de amistad, sin embargo, no pasa sólo por un tema los estudiantes en situación de discapacidad en sí, sino también porque es el mismo entorno social que no los incluye en las distintas actividades que se desarrollan en torno a la universidad. Lo anterior porque talvez no se ha intencionado, siendo necesario incluir estos objetivos dentro de un proceso de inclusión integral.

\section{Rendimiento académico}

En las opiniones vertidas en las diferentes entrevistas se pudo apreciar que para los jóvenes en situación de discapacidad el ingreso a la educación superior representa un cambio drástico en su ambiente de estudio y en lo personal, 
debiendo asumir una actitud más autónoma o más adulta al pasar desde el sistema de enseñanza media a educación superior, este cambio se puede observar en la opinión de uno de los entrevistados el cual señala: ha habido un cambio en cuanto al sentido de cómo todos los profes te dicen.... que en el liceo de por sí... como que te dicen... como las cosas, en cambio tú cuando ingresas a la universidad nadie te dice nada... en cambio uno tiene que andar eh, ¿cómo se puede decir?... solo, o más bien arreglárselas solo (E.7, P.80). Este cambio puede ser más drástico para la persona con discapacidad, le exige mayor autonomía, por lo cual necesitará desarrollar mayores destrezas personales para responder al nivel de exigencia creciente de su educación y en su gestión personal, en el cual la colaboración de su entorno social, también resulta fundamental, es decir, las consideraciones de sus profesores en relación a el acceso a la información y metodologías de enseñanza y tipo de evaluaciones, el apoyo de sus pares en tareas específicas e integración a grupos de estudio, y el aporte de su familia frente a la necesidad de realizar actividades de apoyo en el hogar para cumplir las metas de las diversas asignaturas, sin esta adaptación entre la persona, su desempeño ocupacional y su entorno como plantean los modelos ecológicos en el libro de terapia ocupacional de Willard y Spackman (2011), en donde describen el desempeño ocupacional como resultado de una relación interactiva entre las personas, sus ocupaciones y los ambientes en los que viven, trabajan y juegan. Esta relación es de naturaleza dinámica, ya que los tres elementos siempre están cambiando e influyéndose entre sí. En este sentido la adaptación a las exigencias de sus estudios conlleva algunos desafíos mayores ya que los jóvenes en situación de discapacidad, en ocasiones poseen por su misma situación de salud mayores inasistencia, lo cual afecta notablemente en su rendimiento académico. También en lo referente a las necesidades de adaptaciones curriculares menores, lo cual convoca diferentes opiniones de parte de los jóvenes: tuve por ahí un par de profesores que dictaban muy rápido (E. 1, P. 21), o quizás una dificultad un poco mayor ... el profesor usaba mucho pizarrón y no explicaba, entonces eso era un poco complejo para mí (E. 1, P. 23), en esta última frase y mediante las opiniones, podemos señalar que al ingresar a la universidad los profesores tratan con igualdad de condiciones a los jóvenes en situación de discapacidad, frente a sus otros compañeros de curso, como lo señala uno de los entrevistados: no acá todos somos iguales (E. 4, P. 74), esto genera una doble apreciación para los entrevistados, por un lado les gusta porque perciben un trato sin discriminación, ni diferenciaciones: yo nunca he pedido algo diferente al resto porque si bien mi discapacidad es física, yo no tengo ni un impedimento mental, ni retraso, ni nada asi que eso nunca, si se le hubiese pasado por la mente de alguien yo hubiera dicho no, a mí me evalúan igual que el resto (E. 15, P. 34). Por otra parte también demanda a que los profesores tengan una mayor preparación para satisfacer las necesidades a través la metodología de enseñanza, lo cual no quiere decir que se trate de manera distinta que al resto de los estudiantes y generar el concepto llamado discriminación positiva, esto lo señala uno de los entrevistados: si había que reprobar un ramo lo reprobaba, si nunca eh.... aprobé un ramo de una manera porque por mi discapacidad o por lastima, no todo lo contrario... (E. 12, P. 28). Este trato igualitario se percibe altamente valorado por los entrevistados.

En estas conversaciones podemos apreciar que se requiere de acciones que atiendan a las diversas dificultades que presentan los entrevistados para lograr su nivel apropiado de rendimiento académico, en las mismas condiciones de sus compañeros sin discapacidad y que las adaptaciones curriculares y ayudas técnicas son necesarias. Sin embargo la mayoría de los alumnos no quieren ser tratados de manera distinta en cuanto al nivel de exigencia académico, ni ser generadores de lástima o tratos especiales o infantilizados.

\section{Inserción laboral}

En esta categoría, se pudo apreciar que hubo escasas experiencias en el colectivo de investigación, pero en los casos que si existieron, se señala que la discapacidad no resultó ser un impedimento para postular a un trabajo y que existió igualdad de condiciones respecto a las personas sin discapacidad. Igualmente fue vivenciado positivamente en el trato con sus empleadores 
y pares, esto lo señala uno de los entrevistados al comentar: yo creo las relaciones normales que hay entre personas....eh de repente sus diferencias como todo tipo de trabajo, pero si dentro de todo normal (E. 12, P. 44).

Otro factor que se señala entre los entrevistados, es la experiencia positiva que se ofrece al realizar las prácticas profesionales, donde generan un desarrollo y una potenciación de habilidades personales para la inserción socio laboral, esto lo señala uno de los entrevistados: porque se trabaja con experiencia, por la práctica profesional (E. 5, P. 21). Estas experiencias y la buena relación entre el empleador y los compañeros de trabajo, resultan enriquecedoras, donde el ambiente en que se desenvuelve tiene una importancia relevante para la persona y su desempeño ocupacional. Además refleja en un trato la igualdad y solidadridad lo cual comenta uno de los entrevistados: mi jefe y mis compañeros también, porque de repente cuando yo necesito ayuda, ellos no tienen inconveniente en colaborarme (E. 12, P. 68), dentro de esto, los jóvenes comentan como uno de sus objetivos es el poder lograr una buena situación económica mediante la obtención de un título y un trabajo estable, en ese ámbito señalan que de acuerdo a su experiencia no ha habido discriminación de salario en sus experiencias, al momento de ingresar a un trabajo y que éste es acorde al título obtenido.

\section{Facilitadores}

De acuerdo a los resultados arrojados por el colectivo de investigación a través del instrumento de la entrevista semi-estructurada, se refleja como principal facilitador el apoyo familiar, seguido por el de los pares y profesores, dentro del proceso de educación superior en la Universidad de Magallanes, uno de los entrevistados señala en relación al apoyo familiar: mi motivo más que para mi vida o para mi futuro, es mi familia, el darle las gracias por estar ahí, el apoyo constante (E. 15, p. 2), lo cual deja en evidencia el agradecimiento a su familia, como fuente de apoyo e inspiración para continuar sus estudios y aspirar a mayores desafíos, así como también, que la ayuda y apoyo por parte de profesores y compañeros de curso logra facilitar el proceso académico, permitiéndole sentirse comprendido y aceptado, según señala un entrevistado: Cualquier compañero aunque no hable con él o no, o me lleve muy poco también me ofrece su ayuda, entonces en el caso de los hombres yo me aferro a sus mochilas, en el caso de las mujeres me dan su brazo y me acompañan al paradero (E. 14, p. 92), los compañeros o pares logran entregar el apoyo necesario que requiere para realizar ciertas actividades, lo que beneficia a su vez, las relaciones sociales entre ellos.

De esta manera, la teoría de la Resiliencia señalada por Cyrulnik (2003), que hace referencia a la capacidad de las personas para enfrentar un obstáculos, adversidades o traumas, resalta la actitud presentada por los alumnos frente a los desafíos, un entrevistado comenta; tiene que darse a la persona con discapacidad la posibilidad de demostrar eh..si se las puede o no (E. 1, p. 127), esta frase denota que las personas con discapacidad se enfrentan constantemente a obstáculos a lo largo de su vida, mientras existen personas que tienen el temor de correr riesgos y reprimen a veces acceder a lo que les gustaría hacer, de esta manera, lo cita un entrevistado; acá en Punta Arenas, por lo que he visto la gente que tiene diferentes dificultades, no se motiva para estudiar más allá, llegan a la media y se quedan ahí, entonces no intentan de correr el riesgo (E. 13 P. 16).

Se rescata en algunos entrevistados la importancia que tuvo para ellos previo a la educación superior, el programa de integración escolar (PIE), donde sentían un apoyo por parte de la institución y de sus profesionales, en Chile este programa que se instauró en el año 2003 y entrega apoyo a alumnos de educación básica y media, lo cual para ellos significó de gran ayuda en inclusión, desarrollo académico y social, de esta manera lo señalan los siguientes entrevistados: estuve en el Politécnico y en el liceo y ahí habian grupos de integración para personas con discapacidad y nos ayudaban con el tema de los trabajos, las pruebas, gente como capacitada en educación especial, para que, pa ayudarnos po (E. 11, P. 34). En el liceo tenía el apoyo de las técnicos, o sea ellas me ayudaban, tenía una profesora que estaba al lado mío, me escribía la materia, me explicaba y así po (E. 13. P. 68). En la educación superior no sucede así, por lo que deja en evidencia una falencia, al no existir programas específicos de apoyo a la discapacidad, al menos en 
nuestra universidad, que entreguen las estrategias necesarias de apoyo al proceso académico.

Otros resultados arrojados por las entrevistas, son la utilización de adaptaciones y ayudas técnicas, la cual hacen referencia a lo fundamental que es para el proceso de inclusión de los alumnos con discapacidad y de esta manera facilitar el proceso académico, estas adaptaciones comprenden el acceso a la información dentro de la universidad, tanto como en la biblioteca, el acceso a libros y documentos que son fundamentales para el conocimiento y estudio, como también, aquellas ayudas técnicas en el caso de personas con discapacidades visuales, como computadores con software como el Jaws, también aquellas adaptaciones por parte de los profesores en la metodología pedagógica, la cual incluya la diversidad dentro del aula. Los beneficios por parte del estado y la institución, tales como, las becas que se entregan a los alumnos, logran disminuir la carga económica, tanto en la familia como en el estudiante, en el caso de la Universidad de Magallanes, esta hace entrega de la beca de discapacidad, aun así algunos entrevistados refirieron tener dificultades en este ámbito, o no haber tenido conocimiento, algunos alumnos ingresan a la universidad por vía de notas, lo cual da como consecuencia la perdida de ciertos beneficios como las becas, de esta manera lo comenta el siguiente entrevistado: yo entré sin prueba, entonces no pude acceder a los beneficios (E. 1, P. 111), los 4 primeros años, claro hubo que pagar, entonces esa es una desventaja porque si no entras por el sistema de ingreso regular, no puedes dar la prueba (E. 1, P. 121).

Se concluyen así, que dentro de los facilitadores se mencionan tanto el apoyo familiar, académico, las ayudas técnicas, apoyos económico y de sus pares, todos los cuales son percibidos como apoyadores del proceso de inclusión en la educación superior de los estudiantes en situación de discapacidad de la Universidad de Magallanes.

\section{Discriminación}

En cuanto a la categoría de discriminación se obtuvieron diversos resultados, destacando la falta de conocimiento por parte del entorno universitario, en general acerca de la discapacidad y las diversas patologías existentes, sobretodo se reconocen solo aquellas que son visibles como la discapacidad física y sensorial. Es importante que los pares y académicos accedan a esta información previo al ingreso de un alumno con discapacidad, para así lograr mayor preparación y eliminar los prejuicios o mitos que aparecen en el momento de interactuar con los alumnos, debido a que en el colectivo de estudio, señalan notar estos cuestionamientos o prejuicios por parte de sus compañeros y profesores, en distintas situaciones, así como refiere uno de los entrevistado: la gente que ve, tiene esa idea de que los ciegos no pueden subir escaleras, entonces alguien después me comento eso y yo me enrabie, yo digo oh si supieran cuanto tengo que subir para llegar a mi oficina (E. 1, P. 246). De esta forma, derribar conceptos culturalmente arraigados asociados a la falta de capacidades o "incapacidad" de realizar ciertas cosas, lo anterior es necesario para lograr una inclusión en la educación superior y así también, estar preparados como sociedad en general para incluir a personas en situación de discapacidad y no ir solucionando los problemas o barreras sobre la marcha, tal como lo señala el mismo entrevistado; esas cosas las hicieron obviamente después de que entró él, porqué en este país somos súper reaccionarios, pasan las cosas y ahí hacemos los cambios, entonces, en vez de adelantarnos (E. 1, P. 195).

De acuerdo a la justicia ocupacional, la que reconoce a los seres humanos como seres ocupacionales, los cuales necesitan y quieren participar en ocupaciones con el objetivo de desarrollarse y prosperar, este concepto, está a favor de la facilitación de diferentes accesos a oportunidades y recursos con el objeto de considerar de las diferencias individuales resultantes de la interacción biológica y humana con su medioambiente natural (Standyk et al. 2010), de acuerdo a esta definición y a la cita anterior, podemos darnos cuenta que estas facilitaciones en algunas ocasiones no se encuentran presentes, debido a no estar previamente ni completamente preparados para la diversidad, hablar de igualdad $e$ inclusión es un tema aún en desarrollo, así lo refiera uno de los entrevistados; cuando uno tiene discapacidades, es difícil pretender un trato igualitario, porque siempre va a tener uno una dificultad más o vas a requerir alguna ayuda que la institución, si te la da hay un trato 
preferencial y si no te la da también hay un trato discriminatorio o desigual porque en el fondo si no te da la ayuda a ti te cuesta más (E. 1, P. 165).

Eliminar prejuicios, mitos y términos que desvaloricen a la persona por su discapacidad, son temas que se deben abordar para poder hablar de inclusión y hacer valer a el ser humano por su esencia, valores y conocimientos y no por sus características particulares, así refleja la evolución del concepto de discapacidad con el siguiente entrevistado: el término impedido es distinto, el término impedido es como que no puedes nada, pero eso se ha ido cambiando, y harto (E. 11, p. 41), el estigma de la discapacidad aunque se reconoce como en evolución, igualmente refleja la existencia de prejuicios, como se comenta en la siguiente frase: pero a ver, por no decir, no sonar feo, pero si había algunas docentes que nunca... en un principio, como que quizás dudaron un poquito de cómo mis capacidades... por decirlo asi (E. 9, P, 16).

Por otro lado, existen distintos tipos de discapacidades, sin embargo, la sociedad generalmente asocia a una persona con discapacidad a la discapacidad física o sensorial, sin reconocer otro tipo de discapacidades, esto se refleja al momento de entregar apoyo o en el caso de las personas que se encuentran estudiando, al momento de interactuar con sus compañeros o en la metodología pedagógica de los académicos, así lo señala el siguiente entrevistado; o sea si tú ves una persona en la calle en sillas de ruedas es como que, ha ya, la vamos a ayudar y todo bien...ni un, ni un problema pero de repente hay personas como que si tú me ves tú dirías que soy una persona normal, sana (E. 2, P. 125). Es por esto, algunos alumnos que no tienen una discapacidad física o sensorial, tienen la sensación de que existe una preferencia en cuanto los beneficios o apoyos que se otorgan.

Por último, se obtuvieron comentarios vinculados a la discriminación por causa de la discapacidad, vivida en distintos contextos, esto se puede ver reflejado en lo que nos hace referencia la siguiente cita; a lo largo de mi vida me han discriminado, siempre lo tendré presente, entonces obvio el rechazo por parte del otro... siempre va a estar (E. 15, P. 12).

\section{Resiliencia}

Una de las principales características de la resiliencia, es salir adelante a pesar de la adversidad, característica que aparece en la gran mayoría de los estudiantes entrevistados, quienes se han sobrepuesto a diversos obstáculos producto de su situación de discapacidad y ahora en particular en el ámbito de educación superior, así lo refiere uno de los estudiantes entrevistados: si, obvio es que yo creo que cuando uno quiere salir adelante, más que nada depende de uno y uno ir eliminando las barreras que hay en el entorno, porque como te decía, no había ningún tipo de inclusión en ese entonces para discapacitados (E. 12, P. 8). Aquí se destaca, que principalmente la capacidad de salir adelante, así como eliminar las barreras del entorno, depende principalmente de la actitud y la motivación que éste presente. Además, la perseverancia es otra característica que aparece en los entrevistados, con la meta de sacar adelante sus estudios a pesar de la adversidad o dificultades con que se encontraron. Por otra parte, algunos plantean en forma crítica, que en su proceso educativo no siempre han encontrado un ambiente de inclusión, sino también barreras, frente a las que se ha visto enfrentado.

Por otra parte, algunos de los estudiantes entrevistados, refieren que en la mayoría de los casos, los docentes no están preparados para trabajar con estudiantes en situación de discapacidad y no se dan el tiempo para explicar de manera más personalizada a aquellos alumnos que requieren de mayor atención. Ante estas dificultades, los estudiantes deben utilizar estrategias personales para salir adelante, como lo refiere uno de los entrevistados: eh, lo que pasa es que como no entendía, eh, tomaba nota de algunas cosas y después tuve que tomar clases particulares, esa... eso fue lo que tuve que hacer en ese ramo (E. 1, P. 25), otro de los entrevistados refiere: y lo otro bueno fue el caso de los libros, bueno ponerme a escanear no más, si al final uno con refunfuñar no gana nada, si hay que hacer las cosas y bueno ponernos a escanear todos, bueno manos a las obras, chuta no sé, yo creo que dentro de todo tengo esto que los psicólogos llaman resiliencia (E. 1, p. 205).

De acuerdo a los párrafos antes 
mencionados, aparecen características propias de la resiliencia, tales como, la capacidad para la adaptación en un ambiente cambiantes, y a veces adversos, así como la actitud proactiva y búsqueda de estrategias personales para la equiparación y la perseverancia, en el no abandonar sino continuar hasta el logro de su meta. Por otro parte también se aprecia un desconocimiento en relación a sus derechos como estudiantes dentro de la legislación existente al torno de la inclusión en educación (Ley 20.422, art.3).

\section{Barreras}

De acuerdo a lo expuesto en el marco teórico, se ha producido un avance social tanto en la definición del concepto de discapacidad como en el proceso de inclusión de las personas en los diferentes contextos donde se desenvuelven, sin embargo, aún existen barreras o dificultades que les impiden un desempeño independiente. En esta categoría de investigación, constatamos como a pesar del avance que ha tenido la Universidad de Magallanes en el proceso de inclusión, desde los primeros ingresos, es necesario considerar la accesibilidad y el diseño universal a la hora de diseñar, planificar y llevar a cabo la construcción o adecuación de los distintos edificios para reducir al mínimo posibles barreras arquitectónicas que dificulten la participación.

Accesibilidad, es el conjunto de características que debe disponer un entorno urbano, edificación, producto, servicio o medio de comunicación para ser utilizado en condiciones de comodidad, seguridad, igualdad y autonomía por todas las personas, incluso por aquellas con capacidades motrices o sensoriales diferentes (Boudefuer \& Squella, 2010).

La ley 20.422 contempla los principios de accesibilidad universal y diseño universal como:

- Accesibilidad universal: La condición que deben cumplir los entornos, procesos, bienes, productos y servicios, así como los objetos o instrumentos, herramientas y dispositivos, para ser comprensibles, utilizables y practicables por todas las personas, en condiciones de seguridad y comodidad, de la forma más autónoma y natural posible.

- Diseño universal: La actividad por la que se conciben o proyectan, desde el origen, entornos, procesos, bienes, productos, servicios, objetos, instrumentos, dispositivos o herramientas, de forma que puedan ser utilizados por todas las personas o en su mayor extensión posible.

Al definir las categorías apriorísticas de la investigación, se contempló como una de ellas, la categoría ambiental que considera las sub categorías de barreras arquitectónicas y de accesibilidad y la de facilitadores arquitectónicos. De acuerdo a los hallazgos investigativos resultantes de las entrevistas realizadas al colectivo de estudio, podemos concluir respecto de la sub categoría de barreras arquitectónicas que en la Universidad de Magallanes se encuentra en proceso de mejorar la accesibilidad, situación que aún está lejana del ideal, entre otros aspectos es necesario mejorar rampas, estacionamientos y senderos, así como facilitar el acceso a pisos superiores en algunos edificios que no cuentan con ascensor, mejorar la implementación de baños accesibles y los sistemas de información y orientación para personas con discapacidad sensorial, para identificar edificios, salas, baños, oficinas, etc. Todo esto, con el fin de favorecer el desplazamiento dentro de la Universidad, permitiendo el acceso e independencia por parte de los estudiantes en situación de discapacidad a la totalidad de las instalaciones universitarias.

De acuerdo a lo comentado por algunos de los estudiantes entrevistados;... no hay ninguna marca en braille, los números de las salas, que hay baño de hombre o mujeres, la biblioteca (E.1, P.189), ...pero si, siempre encontré que era una dificultad, en la universidad no hay suficientes baños para personas con discapacidad (E.1, P.191),... bueno, las barreras arquitectónicas, de repente me tocaba clases en un segundo piso, tenía que subir, mis compañeros me ayudaban, más que nada eso, barreras arquitectónicas (E. 12, P. 32), de esta forma se evidencia, como los estudiantes con discapacidad, identifican las barreras y dan sugerencias para mejorarlas.

A su vez, al realizar las entrevistas, se obtuvieron hallazgos de investigación que 
permiten crear la categoría emergente de barreras, considerando las barreras económicas, tecnológicas, climáticas y familiares, además de las barreras arquitectónicas.

En las barreras económicas, se evidenció como algunos estudiantes debido a su discapacidad, no pudieron rendir la prueba de selección universitaria (PSU), no teniendo la opción de postular a los beneficios asociados a esta, como becas y créditos estatales y teniendo, por lo tanto, que cubrir la totalidad de los gastos asociados al arancel universitario, una de las sugerencias nuestras era de que haya una prueba porque yo entré sin prueba entonces no pude acceder a los beneficios (E. 1, P. 111) y esto significó cancelar el arancel los cuatro primeros años claro hubo que pagar, entonces esa es una desventaja porque si no entras por el sistema de ingreso regular no puedes dar la prueba (E. 1, P. 121).

Otro costo asociado al estudios y posterior acceso al mundo laboral de las personas con discapacidad, es la adquisición de ayudas técnicas necesarias para la equiparación de oportunidades, como son intérpretes de señas, profesores particulares, notebook especiales, softwares, grabadoras, entre otros, lo que se manifiesta en las siguientes frases;... igual estuve 3 años con interprete y que pagó SENADIS, de los 4 años que estudie psicopedagogía en otra institución... un año... me pagaron al intérprete primer año, igual postule a SENADIS pero como persona... pero solo, segundo año postulo como estudiante de otro Instituto de Educación superior yo solo pagaba, pagaba a mi intérprete (E. 5, P. 46), otro entrevistado comenta; pero el consejo (las autoridades) se arriesgó conmigo, porque me compraron computador, con escáner, eh...así que me, me compraron incluso el Jaws original (E. 1, P. 235) de esta forma se relata la necesidad de acceder a ayudas técnicas las cuales resultan indispensables para estos estudiantes.

En este sentido cabe destacar la importancia del apoyo de SENADIS a través de los proyectos de ayudas técnicas, sin las cuales sería muy difícil para los estudiantes lograr equiparar sus competencias, y lograr sus objetivos académicos.

Las barreras tecnológicas dicen relación con la calidad de las herramientas tecnológicas existentes y la falta de implementación de éstas, principalmente de proyectores en mal estado y sin las características técnicas adecuadas, para personas con discapacidad visual por ejemplo la falta de bibliografía digitalizada y/o en sistema braille, un entrevistado comenta;... no poder acceder a los libros, que no hayan libros digitalizados (E. 1, P. 169), ahi es parte de la infraestructura y los implementos que usa la universidad, los data que yo he visto son malisimos, ósea, eh, por ejemplo en el Instituto hay datas buenísimos, ósea esos tienen un brillo adecuado, tamaño adecuado, no había problema, en cambio acá llegue, eh, los datas en principio malos, unos tiene que andar adecuando, subirse a una mesa, balancearlo toda la cuestión, y el brillo malísimo, entonces eso es otro factor, el brillo, el tamaño de la proyección, eso va variando "cachay", también los telones eh, hay por ejemplo en algunas salas.. no hay ningún telón (E. 11, P. 52)

Las barreras climáticas propias de vivir en esta región austral, que principalmente se evidencian en época invernal, como son, pocas horas de luz natural, fuertes vientos y senderos escarchados, factores que si bien son externos e incontrolables, sus efectos pudiesen ser mitigados, implementando por ejemplo, mejores luminarias o diseñando "para vientos", ocupando sal para escarcha y caminos pavimentados para comunicación entre los distintos edificios. Esto se plasma en los siguientes comentarios de los entrevistados; ...el mayor problema que tengo, es la distancia entre los edificios de la universidad, porque yo puedo caminar, pero me demoro entonces llego tarde a la clases, y en la escarcha en invierno, esto es peor que una pista de patinaje y mis compañeros eran buena onda y me ayudaban, pero te repito uno prefiere hacer las cosas solo (E. 11, P. 30), ... cuando llega aquí uno en la U en la mañana a las ocho, cuando esta oscuro en horario de invierno o cuando uno sale a las cuatro de la tarde en horario de invierno (E. 14, P. 90)

En relación a las barreras familiares, se observa muchas veces sobreprotección familiar, el no permitir que los estudiantes se desenvuelvan de acuerdo a sus intereses con sus pares el ambiente universitario, por ejemplo en el siguiente caso;... porque empecé a trabajar, entonces mi mamá me dice no trabajes, mientras pueda estudiar no trabajes y también a veces me dice no pololees 
porque si pololeas vas a dejar de estudiar, no, no mires animé porque te distrae, entonces, siempre anda diciendo cosas... entonces que a mí la verdad no, no quiero que me las diga, por más que, por más que quieran intentar hacer algo, pero a mí me da... me molesta porque si $y$ claro me dice si tú quisiste estudiar, estudia no más, y entiendo eso, pero también quiero hacer otras cosas, hay gente que hacen como 40, 50 cosas a la vez y les va bien en la universidad, por qué yo no? Porque quiere, porque quiere que yo lo único que haga es despertarme, ir a estudiar, venirme a la universidad, y estudiar de nuevo, volver a mi casa y estudiar de nuevo....eh muy monotemático, a mí no me gusta tener un estilo de vida así (E.8, P. 94). En este caso se observa sobreprotección y limitación de la autonomía del joven ya que la madre no da oportunidad de realizar ninguna actividad que no sea académica, restringiendo la participación y socialización normal de su hijo de acuerdo a su etapa de desarrollo.

\section{Ocupación y proyectos personales}

La categoría emergente, denominada ocupación significativa y proyectos personales, nace a raíz del análisis de las ocupaciones en que las personas del colectivo de estudio se involucran paralelamente a sus estudios universitarios y el significado que estas actividades y su proyecto de ser un profesional representa para ellos.

Según la Canadian Association of Occupational Therapist, las ocupaciones se refieren a "grupos de actividades y tareas de la vida diaria, denominadas, organizadas y con un valor y significado dado por los individuos y una cultura. La ocupación es todo lo que las personas hacen para ocuparse de ellas, e incluye cuidar de su persona (auto cuidados), disfrutar de la vida (ocio) y contribuir a la fábrica social y económica de sus comunidades (productividad)", de acuerdo a esto se puede apreciar en las verbalizaciones de algunos de los entrevistados que denotan la importancia y significancia que el hecho de estar estudiando en la educación superior representa para ellos, por ejemplo en la frase;... em, bueno yo desde chica que mi meta era estudiar en la universidad, por un tema quizás como...de familia, fui como una primera persona dentro de mi familia en entrar a la universidad, entonces esa era como mi meta y objetivo, así que y bueno gracias a Dios, temía como me iba a ir, me fue bien siempre en mi enseñanza tanto básica como media, no tuve problemas después para...para ingresar, para prepararme para la PSU y posteriormente hacer la postulación (E. 9, P. 8). A su vez, se observa que el estudiar representa un proyecto compartido con sus redes más cercanas, principalmente la familia, como se aprecia en la siguiente frase;... habia que leer, estudiar y reforzar en la casa y la profesora, y los dos con mi mamá llorábamos porque era tan diferente, era la estructura diferente o sea imaginate en ese tiempo decía ciencias naturales; la montaña, el relieve todo ya eso, tenía que leer un texto... como entendía solo con verlo?... que hacia la mamá, lo dibujaba o lo iba escribiendo, y muchas veces yo lloraba, y un día dijo mamá: Vamos, vamos tu puedes!... lo importante acá es la familia, ¿y qué pasa hoy día con los que son sordos... que pasa?, la gran mayoría se separa de la familia (E. 5, P. 13). Como se puede reconocer, se manifiesta la importancia el compromiso de la familia como soporte proceso de lograr sus objetivos, son sus madres y padres quienes se involucran en el proceso de estudio con el objetivo de disminuir las barreras al desempeño de sus actividades y equiparar las oportunidades del estudiante.

A su vez, se evidencia la importancia que se le asigna al ámbito académico y como éste, en sí mismo, y más allá de lo académico constituye la principal ocupación, para algunas personas del colectivo de estudio, en el párrafo;... si, hago harto deporte, en el colegio atletismo 100 y 800 metros. Este año lo deje. Eh también natación, eso ya desde $8^{\circ}$ básico, ahora no porque más que nada por la universidad... dejé varias cosas de lado (E. 13, P. 79), también se denota su preocupación por no descuidar sus estudios y bajar su rendimiento, ya que mantenerse requiere un esfuerzo al parecer mayor que el de sus compañeros; ... pero de repente en algunas clases que tengo con ellos los veo, hablamos, no se po. Sé que por ejemplo me invitan pa salir a carretear y yo voy de repente, pero cuando no hay evaluaciones y esas cosas (E. 13, P. 72).

También se observa que presentan, como cualquier otro estudiante, el deseo de continuar los 
estudios realizar post títulos, etc. como lo constata la siguiente frase;... quiero hacer post títulos y magister, pero este año quiero trabajar (E. 5, P. 51)

A su vez, pudo observarse en algunos casos, como las expectativas de estudio de los entrevistados, se deben adaptar a la oferta académica existente, esto cuando no incluye las carreras que ellos pretendían estudiar. Al revisar frases como: eh... Bueno más que nada tenía pocas opciones porque acá no están todas las carreras, lo que a mi me gusta está en Santiago, entonces más que nada lo tome como una posibilidad también para mí, por la dificultad que tengo que es la visual (E. 13, P. 4), sin plantearse la posibilidad en este caso de estudiar fuera de la región o lejos de sus familias, posiblemente por la aún existente cierto grado de dependencia familiar o insuficiente autonomía, para pensar en esa opción.

En cuanto a las actividades de ocio y tiempo libre realizadas por los estudiantes, en general pocas, ya que consumen gran cantidad de su tiempo a las actividades académicas, como lo refiere el siguiente entrevistado;...lo único extra que se puede decir que hice que cuando estaba en la universidad pero esto era fuera si de la universidad y practicaba judo (E. 1, P. 99) y durante el año que estuve pal grado igual me iba a entrenar para salir de la casa porque era lo único que hacía era estudiar y ir ahí (E.1, P. 107). Con lo señalado anteriormente, se puede observar que algunos de los estudiantes entrevistados, disfrutan de momentos que les permitan abstraerse del ámbito académico, salir de la rutina y relajarse pero en general, su energía es casi íntegramente consumida por el esfuerzo puesto en lograr mantenerse en igualdad de condiciones en relación a sus compañeros sin discapacidad. Teniendo además pocas oportunidades de socializar fuera del contexto universitario.

\section{CONCLUSIONES}

La presente investigación tuvo como objetivo conocer desde la perspectiva de los propios actores aspectos de la experiencia vivida en el proceso de inserción en el ámbito de la educación superior en la Universidad de Magallanes, lo anterior a la luz de la ciencia de la ocupación, los modelos ecológicos de la terapia ocupacional y la teoría de la construcción social.

Desde este enfoque los datos aportados por 15 estudiantes con distintos tipos de discapacidad, fueron agrupados en categorías de relaciones humanas, participación social, rendimiento académico, ambiente e inserción laboral.

Los discursos de los entrevistados presentan experiencias diversas con mayor o menor grado de inclusión, sin embargo hay aspectos importantes de destacar como la importancia del entorno social el cual cuando es favorable facilita de manera importante la experiencia universitaria y por el contrario cuando este no es muy receptivo a la diversidad genera mayores dificultades, las que se expanden desde lo social al ámbito académico. Desde esta perspectiva cuando los pares y docentes no favorecen la equiparación de oportunidades esto repercute en el ánimo y rendimiento de los alumnos.

La mayoría de los alumnos no logra insertarse lo suficiente en grupos de pares $y$ pocos de ellos participa en actividades extra programáticas, dedicando mucho tiempo a sus estudios y muy poco a actividades de esparcimiento. Aquí observamos que pocos de ellos crean vínculos más profundos o de amistad o relaciones de pajera dentro del ambiente universitario. Con lo que queda de manifiesto una falencia en el desarrollo de programas de intervención que logren el desarrollo personal integral de nuestros estudiantes. Lo anterior difiere de lo encontrado en la literatura en España, donde Ibañez y Mudarra (2004), plantean que, existen muy pocas diferencias significativas en el establecimiento de relaciones de pareja y amistad, en comparación a personas sin discapacidad, participan mayoritariamente en actividades de ocio y tiempo libre, sus aficiones y lugares de diversión son los comunes a su edad y no hay una tendencia significativa respecto a su asociacionismo.

Por otra parte los entrevistados en su totalidad valoran el ser tratados con igualdad al interior de las aulas universitarias, que no se les victimice, ni se les trate con lástima, esperan tener el mismo nivel de exigencia en cuanto a los resultados esperados de competencias en cada una de las asignaturas de sus carreras, sin embargo par esto requieren de adecuaciones curriculares en general menores, que nos siempre son 
consideradas por la totalidad de sus profesores. Valoran también la existencia de apoyos y ayudas técnicas, sin las cuales no podrían lograr sus tareas cotidianas. En el ámbito de inserción laboral hay pocas experiencias, pero las relatadas han sido exitosas.

Las categorías emergentes en los discursos fueron, facilitadores, barreras, resiliencia, discriminación, ocupación y proyectos personales.

Dentro de los facilitadores lo más significativo relatado por varios participantes resulta ser el apoyo familiar, reconocido como un pilar fundamental para el ingreso y progreso del proceso de educación superior, a lo anterior se suman las características personales de los estudiantes en los que se observa la perseverancia y la resiliencia como elementos facilitadores del proceso de inclusión. En forma concreta se hace mención a las ayudas técnicas, apoyo económico y ayudas de académicos y compañeros de curso.

Dentro de las barreras, se comentan principalmente las arquitectónicas que limitan y/o dificultan el acceso libre por todos los espacios de la universidad, así como la necesidad de construir y mejorar las instalaciones existentes para que sean accesibles, refieren falta de recursos bibliográficos digitales y de metodologías inclusivas para la docencia, esto se condice con estudios realizados en nuestro país en relación al tema (Lotito \& Sanhueza, 2011).

Como elemento externo se comenta el clima, de acuerdo a las características de la región, que en los meses de invierno presenta temperaturas extremas que dificultan aún más los desplazamientos, de los estudiantes con discapacidad motora y visual, tanto por la presencia de nieve o escarcha, como por la temprana oscuridad.

Aparece en algunos casos también la actitud sobreprotectora de la familia, como una barrera para el desarrollo de la autonomía y socialización de los estudiantes en espacios más normalizados, es decir actividades de fines de semana o de horario nocturno.

Surge además como categoría emergente haber percibido actitudes de discriminación $y$ prejuicios en relación a su discapacidad, por parte de pares y algunos académicos. Lo cual funciona como una barrera cultural que les afecta.

Por último los entrevistados, valoran de manera muy significativa su rol de estudiantes universitarios, se sienten orgullosos de lo que han logrado y presentan proyectos de realizarse en el mundo laboral y otros de continuar estudios de post grado.

Los resultados obtenidos se relacionan con los presentados en el estudio de percepción de facilitadores, barreras y necesidades de apoyo de estudiantes con discapacidad de la Universidad de Chile (Mella et al. 2013), donde aparecen como facilitadores el apoyo de los compañeros y familia, así como los apoyos brindados para la docencia inclusiva y como principales barreras la falta de conocimiento en relación a la discapacidad y sus estrategias pedagógicas por parte de algunos docentes. También se menciona en este mismo estudio, que "los estudiantes se muestran reticentes frente a la posibilidad de realizar adaptaciones curriculares para facilitar su desempeño académico, lo que se puede relacionar con la baja autopercepción de dificultad manifestada por todos, así como también a la necesidad de tener el mismo nivel de exigencia que sus pares. Esto puede explicarse por la falta de conocimiento sobre sus derechos en igualdad de oportunidades".

En general reconocemos que ha habido avances sustantivos en el proceso de inclusión de personas en situación de discapacidad a nivel internacional y específicamente en nuestro país, y que como universidad estamos avanzando hacia el mejoramiento de este proceso, sin embargo todavía es necesario realizar más esfuerzos por la sensibilización de las personas que no se encuentran en situación de discapacidad y la comunidad en general para abordar esta temática no desde la discapacidad sino desde una perspectiva de derechos humanos, con el fin de hacer efectivas las legislaciones y principios fundamentales que promueven este desarrollo (CRES, 2008).

De acuerdo a revisiones de investigaciones en el área reconocemos que muchas casas de estudios superiores han presentado importantes avances liderando a nivel nacional la inclusión de los estudiantes y la existencia de redes cada vez más consolidadas de instituciones de educación superior que fortalecen los conocimientos y promueven el desarrollo de interesantes proyectos, los cuales son compartidos de manera desinteresada en pro de lograr mejorías a nivel nacional e internacional. 
También destacamos la importante labor que ha realizado y sigue realizando el Servicio Nacional de la discapacidad (SENADIS), con los aportes en el área de ayudas técnicas liderando en muchas regiones el desarrollo de más y mejores oportunidades para las personas en situación de discapacidad.

Sin embargo a través de nuestro estudio, observamos que hay aspectos del entorno social que se mantienen aún sin resolver, que es necesario abordar no solo las necesidades emergentes de los alumnos en el aspecto académico, sino que es necesario fomentar cambios culturales profundos para lograr realmente la inclusión. Es necesario el desarrollo de políticas claras de admisión, progresión y egreso de los alumnos, así como protocolos que establezcan las buenas prácticas y la realización de los ajustes y adaptaciones curriculares necesarias de acuerdo a las características de los alumnos así como lograr el funcionamiento de un programa permanente de apoyo a estudiantes en situación de discapacidad que lidere estos desarrollos.

Cabe destacar que como consecuencia de esta investigación realizada en el año 2013, se logró la adjudicación de un Fondo de desarrollo Institucional, del Ministerio de Educación, MAG 01551, con lo cual actualmente se encuentra en ejecución el proyecto "Acceso, universalidad $e$ inclusión: construyendo una universidad para todos, Universidad de Magallanes", este proyecto busca dar respuesta a necesidades tanto arquitectónicas, digitales $y$ de apoyo individual al estudiante, detectadas a través de las entrevistas y recoge la necesidad de trabajar en el cambio de paradigma social y cultural, que este enfoque amerita.

\section{BIBLIOGRAFÍA}

Alcaide, M. (2009). Influencia en rendimiento y auto concepto en hombres y mujeres. Revista electrónica de investigación y docencia (REID), 2, 27- 44.

Ander-Egg, E. (1986). Diccionario de trabajo social (5 Ed). Buenos Aires: El Cid.

Arreaza, F. (2009). Inclusión y competencias básicas. En: Actas I Congreso Nacional de buenas prácticas de educación, diversidad y empleo. Murcia.

American Occupational Therapy Association (2014). Occupational therapy practice framework: Domain and process (3rd ed ). American Journal of Occupational
Therapy, 68(1), 1-48.

Boudeguer, A., \& Squella, P. (2010). Manual de accesibilidad universal. Santiago de Chile, Corporación Ciudad Accesible.

Brooks, J. G., \& Brooks, M. G. (1999). The courage to be constructivist. Educational Leadership, 57(3), 18-24.

Casal, J., Masjuan, J. M., \& Planas, J. (1989). La inserción profesional y social de los jóvenes. Revista de Educación, 295, 109-122.

Crepeau, E. B., Willard, H. S., Spackman, C. S., Cohn, E. S., \& Schell, B. A. B. (2005). Terapia Ocupacional. Madrid Ed. Médica Panamericana.

Cyrulnik, B. (2003). El murmullo de los fantasmas: volver a la vida después de un trauma. ( $\left.1^{\circ} \mathrm{Ed}\right)$. Barcelona, España, Gedisa.

De Asis, R., \& Palacios, A. (2007). Derechos humanos y situaciones de dependencia. Madrid: Ediciones Dykinson.

De Rojas, C., \& Santos, J. (2005). Mantenimiento y accesibilidad. En Real Patronato sobre Discapacidad y Fundación ACS (Eds.), Manual para un entorno accesible, ( pp, 293-310). España, Industrias Gráficas Caro.

Ferreira, M. A., \& Díaz, E. (2007). La discapacidad: una modalidad inexplorada de exclusión social. En III Congreso Nacional Discapacidad y Universidad. Zaragoza, España.

Ferreira, M. (2008). Una aproximación sociológica a la discapacidad desde el modelo social: apuntes caracterológicos. Revista Española de Investigaciones Sociológicas (REIS), 124(1), 141-174.

Filmus, D. (2005). Desafíos de la Educación para el Desarrollo Humano Integral. La Agenda ética Pendiente de América Latina (9-12). Banco Interamericano de Cultura.

Fondo de Cultura Económica de Argentina.

Fundación Nacional de discapacitados (2011). Discapacidad en Chile. Recuperado de: http://www.fnd.cl/discapacidadenchile.html

Fundación Prevent (2010). Guía para conseguir una prevención de riesgos laborales inclusiva en las organizaciones. Madrid, España.

Ibañez, P., \& Mudarra, M. J (2004) Relaciones sociales de personas con discapacidad en el ocio y tiempo libre. Revista española de psicopedagogía, 229, 521-540.

Juncà, J. (2005). Movilidad accesible. En Real Patronato sobre Discapacidad y Fundación ACS (Eds.), Manual para un entorno accesible, (pp, 97- 237). España, Industrias Gráficas Caro.

Ley 19.284 (1994) Establece normas para la plena integración social de personas con discapacidad. Publicada en El Diario Oficial, del 14 de enero 1994. Chile. 
Ley 20.422 (2010) Establece Normas sobre igualdad de oportunidades e inclusión social de personas con discapacidad. Publicada en El Diario Oficial, 10.Chile.

Lotito, F., \& Sanhueza, H. (2011). Discapacidad y barreras arquitectónicas: un desafío para la inclusión. Revista AUS, 9, 10-13.

Marchant, J. (2004). La discriminación y el derecho a la igualdad. Buenos Aires, disponible en http://www.carlosparma.com.ar/la-discriminacion-y-el-derecho-a-laigualdad/.

Martínez del Castillo, J., Jiménez-Beatty, J. E., Campos, A., Del Hierro, D., Martín, M., \& González, M. D. (2007). Barreras organizativas y sociales para la práctica de actividad física en la vejez. Motricidad European Journal of Human Movement, 19, 13-31.

Mella, S., Díaz, N., Muñoz, S., Orrego, M., \& Rivera, C. (2014). Percepción de facilitadores, barreras y necesidades de apoyo de estudiantes con discapacidad en la Universidad de Chile. Revista latinoamericana de educación inclusiva, 8(1), 63-80.

Méndez, H. (2002). La visión moderna del aprendizaje encarnada en el constructivismo. Recuperado el 2002.

MIDEPLAN (2004). Primer Estudio Nacional de la Discapacidad ENDISC. Edición Gobierno de Chile.

MIDEPLAN (2015). Segundo Estudio Nacional de la Discapacidad ENDISC. Edición Gobierno de Chile.

MIDEPLAN (2015). Segundo Estudio Nacional de la Discapacidad ENDISC 2015. Edición Gobierno de Chile.

Minguijón, J.,Penacho, A.M.. \& Pac Salas, D.(2005). Discapacidad y empleo. ( $1^{\circ}$ edición). Aragón, España. Instituto aragonés de empleo y caja inmaculada.

Moruno Millares, P., \& Fernández Agudo, P. (2012). Análisis de los conceptos teóricos de privación, alineación y justicia ocupacional. Revista Terapia Ocupacional de Galicia, 9, 44-68.

Munist, M., Santos, H., Kotliarenco, M.A., Suárez, E.N., Infante, F., \& Grotberg, E. (1998). Manual de identificación y promoción de la resiliencia en niños y adolescentes. Organización Panamericana de la Salud.

OMS (2001). Clasificación Internacional del Funcionamiento de la Discapacidad y de la Salud. España: Edición Propia Organización Mundial de la Salud. Organización mundial de la salud, Informe mundial sobre la discapacidad. Primera edición. 7. Ginebra, Suiza.

ONU (2006). Convención Internacional de los Derechos Humanos de las Personas con Discapacidad. Recuperado en http: //www.un.org/esa/socdev/nable/documents/ tccconvs.pdf

Parica, A., Bruno, F., \& Abancin, R. (2005). Teoría del cons- tructivismo social de Lev Vigotsky en comparación con la teoría de Jean Piaget. www.pedagogaintegral.blogspot.com/2010_05_01_archive.html.

Piaggio, A. M. R. (2009). Resiliencia. Revista Psicopedagogía, 26(80), 291-302.

Reforma a las leyes de discapacidad: la nueva mirada (2008). Recuperado de: http://www.bcn.cl/ carpeta_temas_profundidad/discapacidad-leyeschile/?searchterm $=$ None

Rodríguez, M., Pereyra, M. G., Gil, E., Jofré, M., De Bortoli, M., \& Labiano, L. M. (2009). Propiedades psicométricas de la escala de resiliencia versión argentina. Revista Evaluar, 9, 72-82.

Salas, M. J. S. (2013). Espacios accesibles en la escuela inclusiva. Revista Electrónica Educare, 17(1), 89-103.

http://www.revistas.una.ac.cr/index.php/educare/issue/current.

Stadnyk, R., Townsend, E. A., \& Wilcock, A. (2010). Occupational justice. En Chrinstiansen, Ch., Townsend, E. (Eds.), Introduction to occupation: The art and science of living $2^{\circ} \mathrm{Ed}$., (pp, 329-358). E.E.U.U. Pearson.

Stang-Alva, M. (2011). Las personas con discapacidad en América Latina: del reconocimiento jurídico a la desigualdad real. Santiago de Chile. Centro Latinoamericano y Caribeño de Demografía (CELADE) - División de Población de la CEPAL.

Taylor, S. Y. B., \& Bogdan, E. R. (1987): Introducción a los métodos cualitativos de investigación. La búsqueda de significados. Sintesis, España. Ed. Paidos.

Townsend, E., \& Wilcock, A. (2004). Occupational justice and client-centred practice; A dialogue in progress Canadian Journal of Occupational Therapy, 71(2), 75- 87.

UNESCO (2007). Situación educativa en américa latina y el caribe: garantizando la educación de calidad para todos. Cap. 3.

UNESCO, I. (2009). Declaración de la Conferencia Regional de la Educación Superior en América Latina y el caribe -CRES- 2008. Unipluriversidad, 8(2). Recuperado de http://aprendeenlinea.udea.edu.co/revistas/index. $\mathrm{php} / \mathrm{unip} /$ article/view/955/828 (2009).

Willard, H. S., \& Spackman, C. S. (2011) Terapia Ocupacional. Buenos Aires. Ed. Médica Panamericana.

Wilcock, A. A. (1998). Reflections on doing, being and becoming/Reflexion sur agir, etre et devenir. Canadian Journal of Occupational Therapy, 65(5), 248-258.

Yerxa, E. J. (1993). Occupational science: A new source of power for participants in occupational therapy. Journal of Occupational Science, 1(1), 3-9. 